يهنهبندى سيلاب شهر بندرعباس و ارزيابى روند تو سعلى نواحى سكونتگاهى به سمت مناطق سيل خيز

\author{
معصومه اسدى":مبربى ثئومورفولوثى، كروه علوم اجتماعى دانشكاه بيامنور، تهران، يران

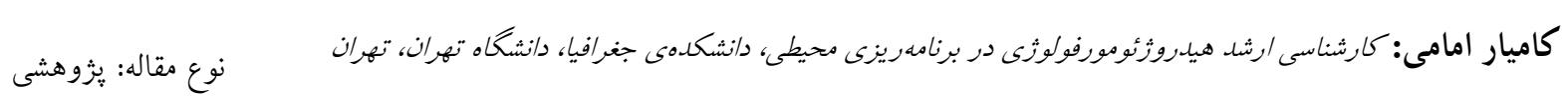

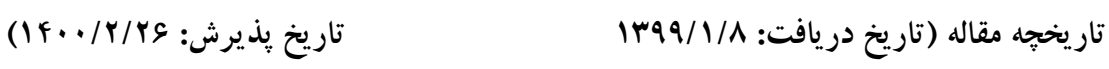

קكيده

سيلابها يكى از مهم ترين مخاطراتى است كه همواره خسارتهاى جانى و مالى زيادى به همر اه داه داشتهل -

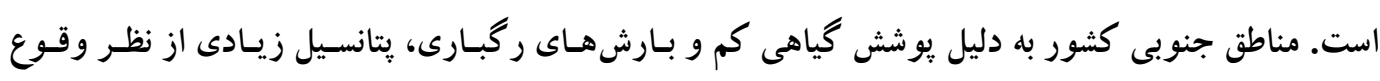

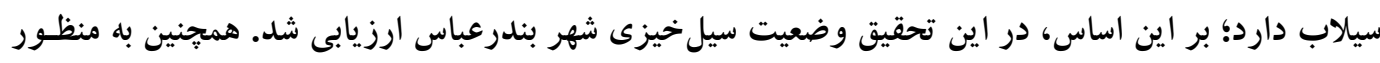

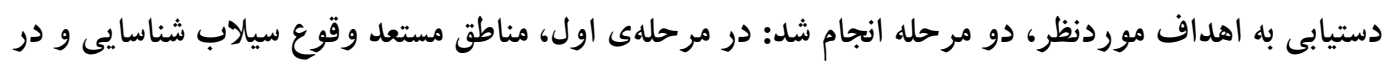

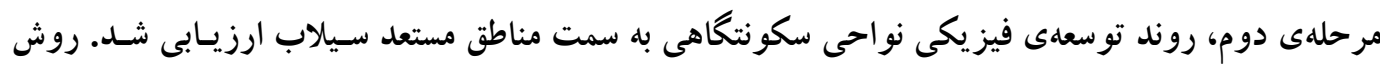

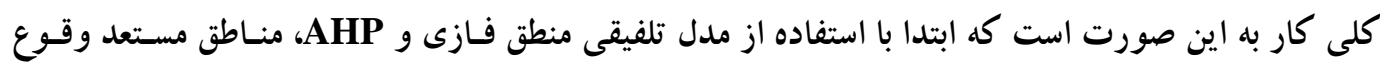

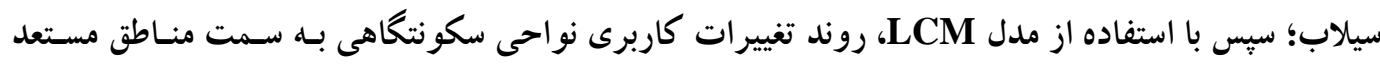

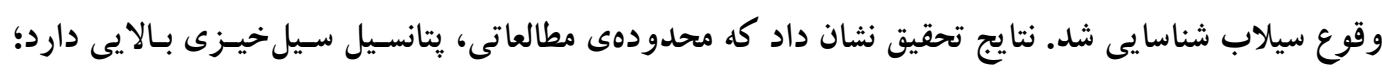

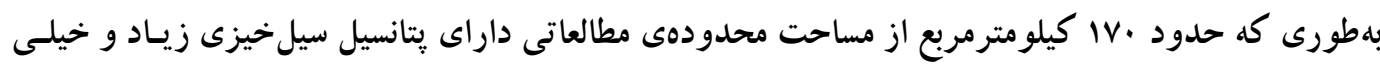

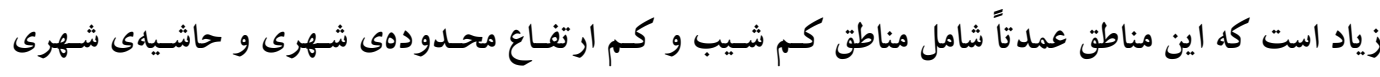

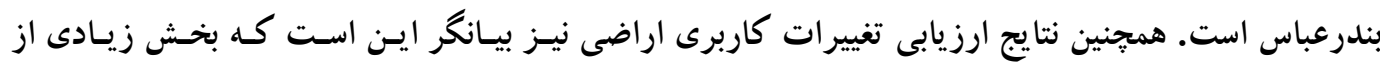

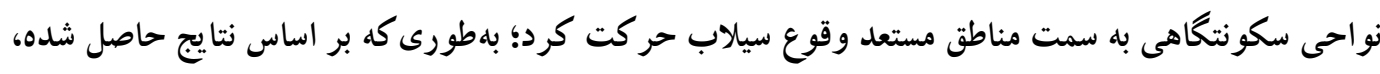

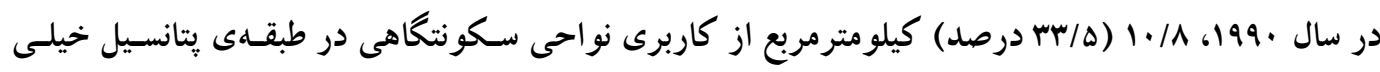

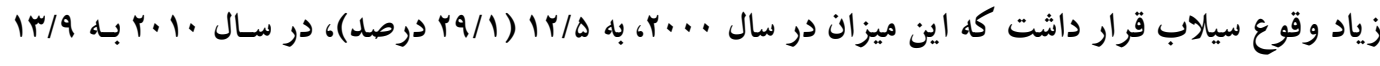

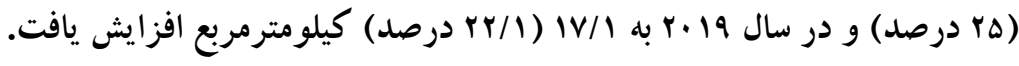

$$
\begin{aligned}
& \text { واز كان كليدى: بندرعباس، تغييرات كاربرى اراضى، سيل. }
\end{aligned}
$$




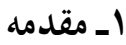

سيل يكى از مهم ترين مخاطرات محيطى است كه همواره خسارتهاى زيادى به همراه داشتهاسـت. بــا توجـهـ بــه

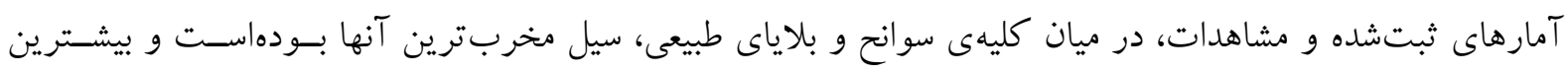

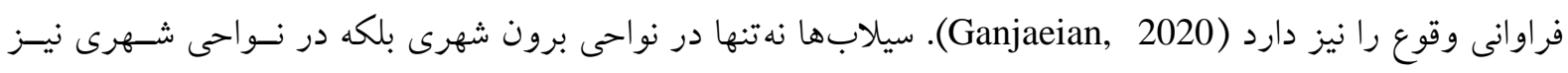

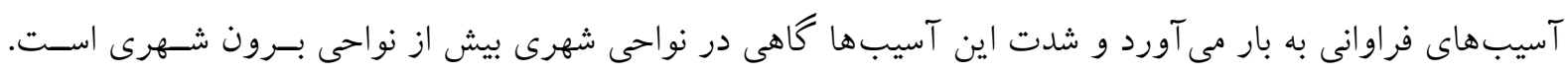

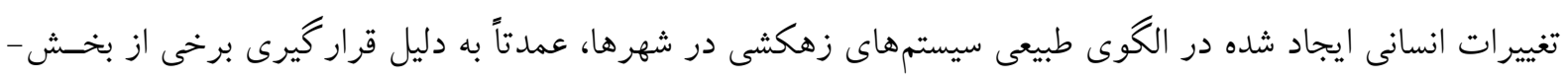

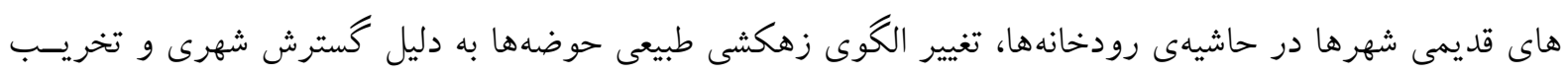

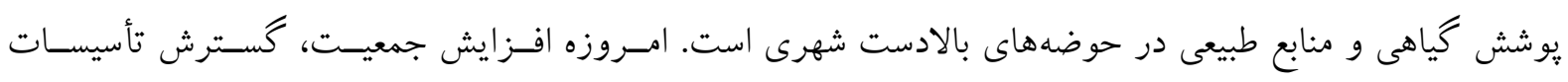
صنعتى، كمبود مكان براى ساختوساز به خصوص در كلانشهرها، به ايجاد تغييرات شديدى در مورفولوزى حوضه إنه

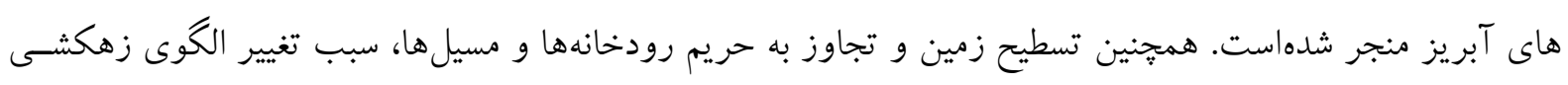
طبيعى و جارى شدن جريان در سطح شهر مى شود (Spehr and kavian, 2014). بررسى شمار وقوع سيل در سالهاى روني

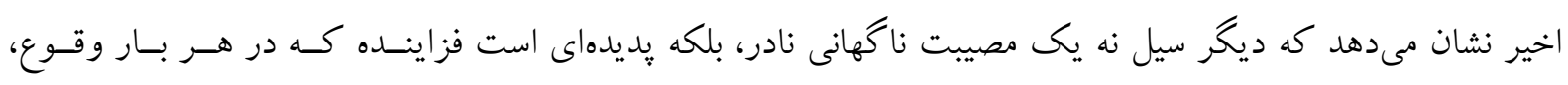

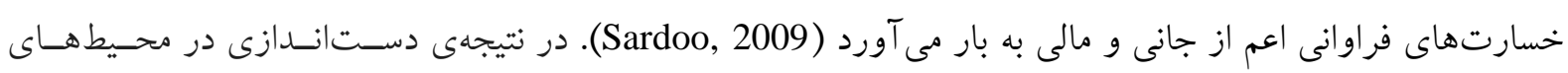

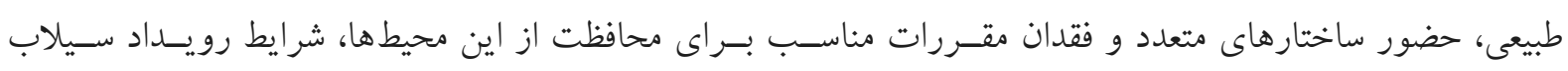
فراهم مى شود. هم:جنين با رشد سريع شهرسازى و ايجاد و توسعلى زيرساخت ها، سيلاب در نـواحى شـهرى بيشـتر و و شديدتر شدهاست (Bhattacharya, 2010). در كشور ما بهخصوص در مناطق جنوبى كشور، سيلابها به دليل شرايط

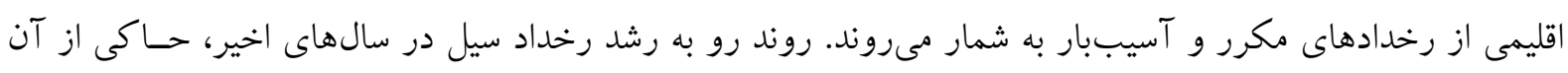
است كه اكثر شهرهاى جنوبى كشور در معرض تهاجم سيلاب قرار دارند. بر اسـاس مطالعـات انجـام شــده، سـالانه

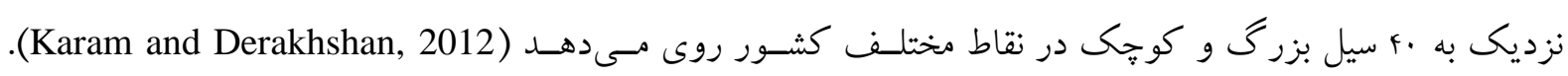
تجارب مطالعاتى و مديريتى كشورهاى مختلف نشان مىدهد كه اولين كام در جهت كـاهش آثـار زيـانبـار سـيل،

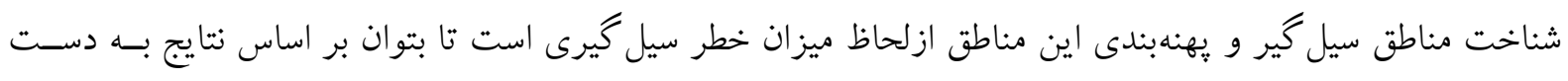

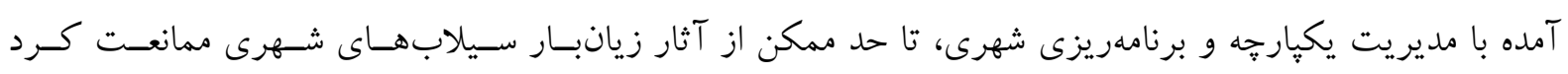

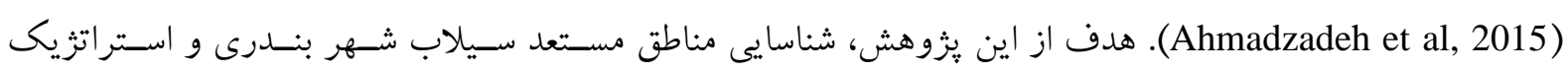

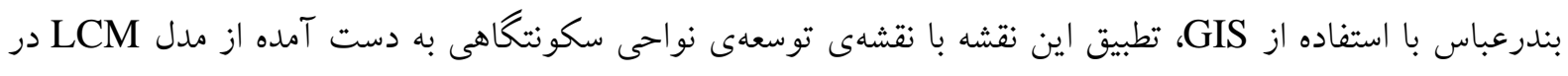

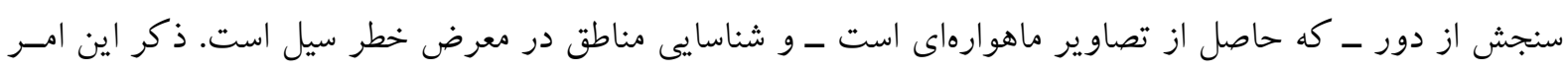

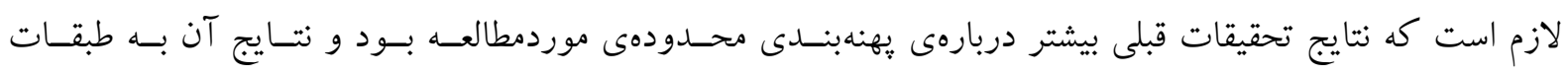

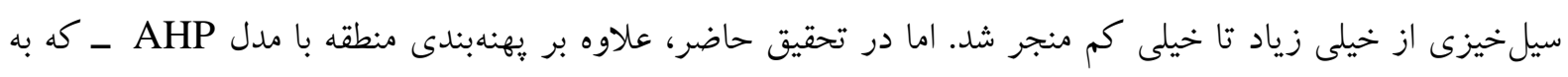

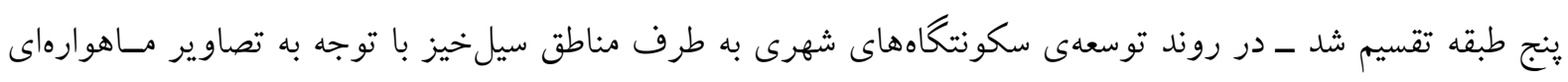

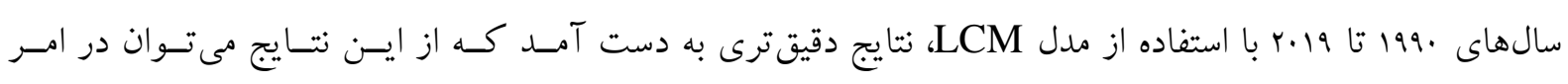
برنامهريزى براى احداث سكونتكاههاى جديد در شهر بندرعباس استفاده كرد. 
در مورد موضوع موردمطالعه، تحقيقات مختلفى در سطح ايران و جهان صورت گرفت كه از جمله آنها مىتوان به

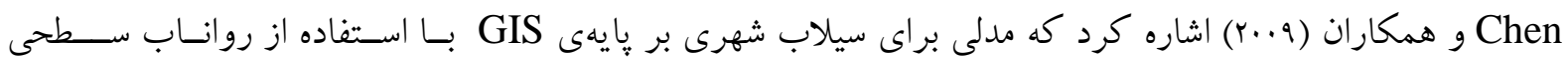

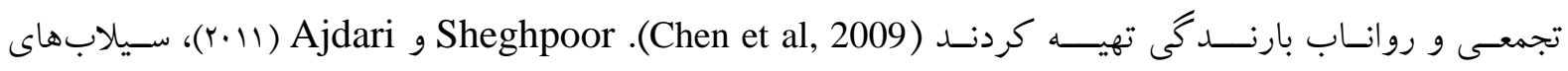

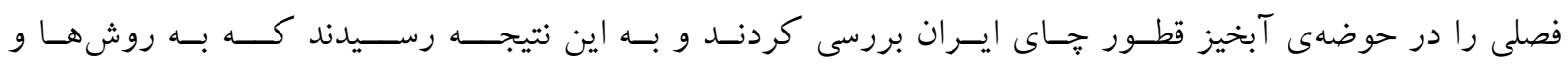

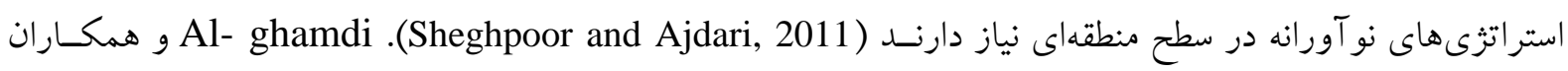

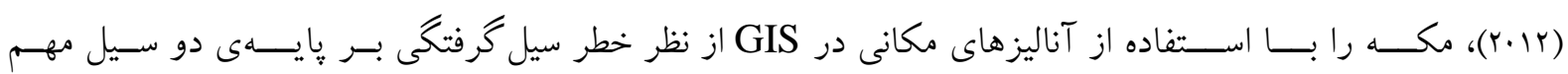

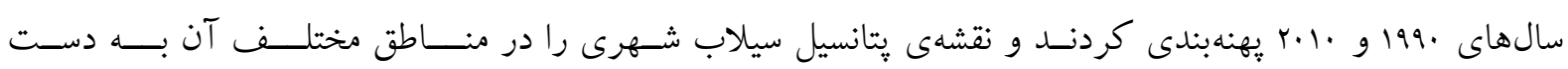

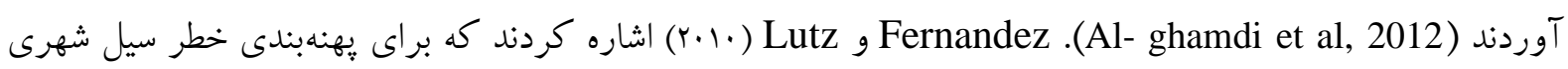

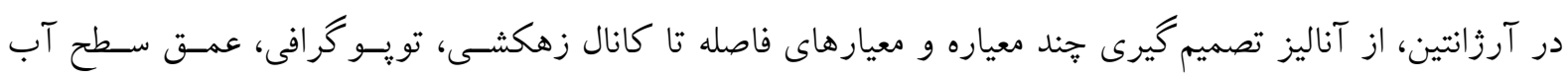
زيرزمينى و كاربرى اراضى، استفاده و نقشهى خطر سيلاب شهرى را ارائه كردنسـ (Fernandez and Lutz, 2010).

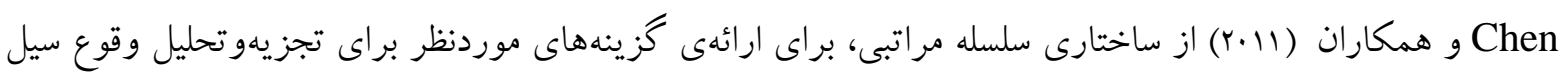
و تهيهى نقشهى خطر سيل شهر تاى تونخ ' تايوان استفاده كردند و به اين نتيجه رسيدند كه ادغام AHP و

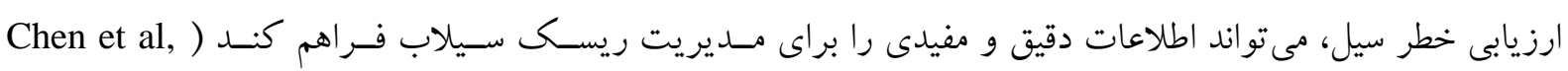

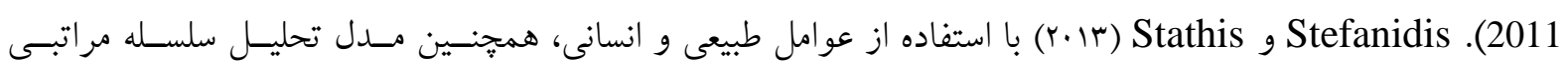
Rahmati .Stefanidis and Stathis, 2013) (AHP)

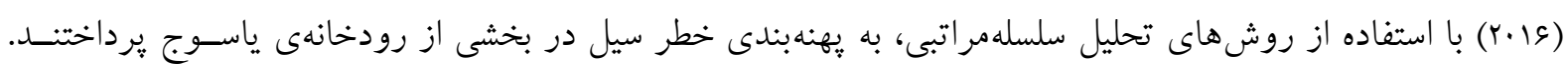

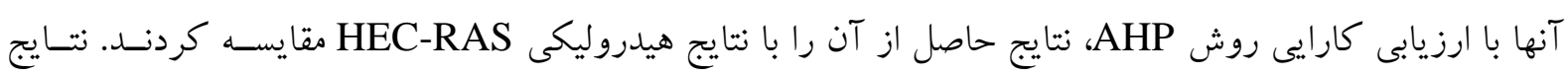

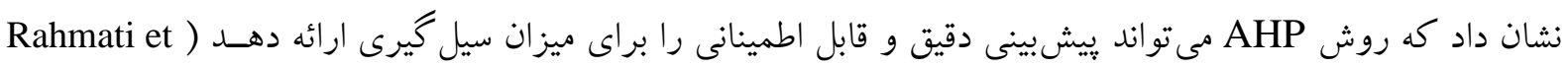

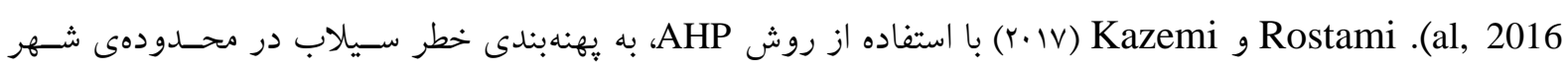
ايلام برداختند. نتايج حاصل از تحقيق نشان داد كه به ترتيب ناحيهى مركزى شهر ايلام و ناحيهى آزاد گان، بـالاترين

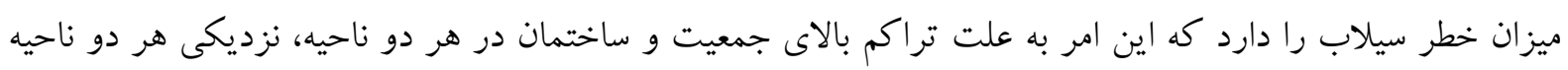

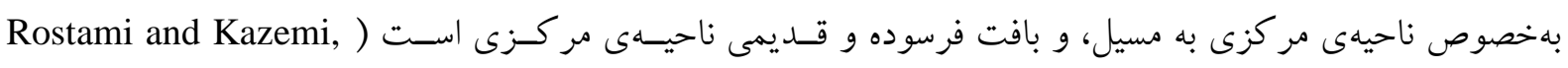

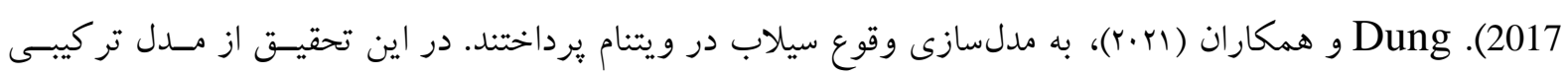

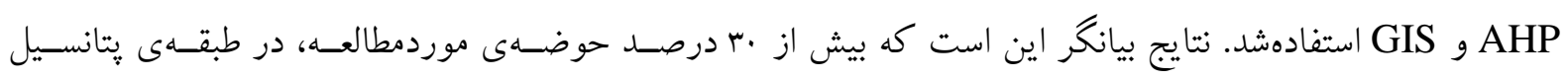

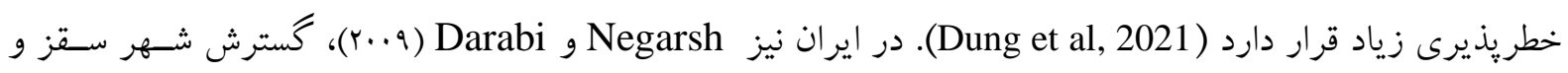

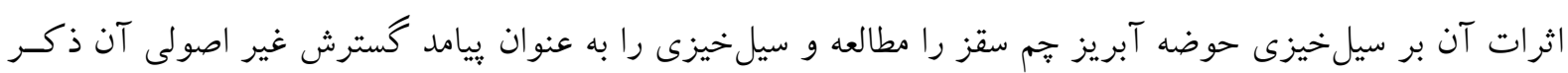

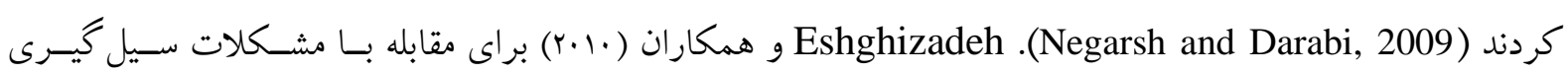

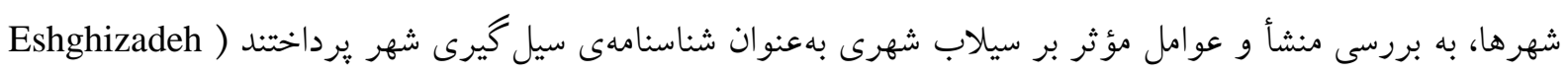

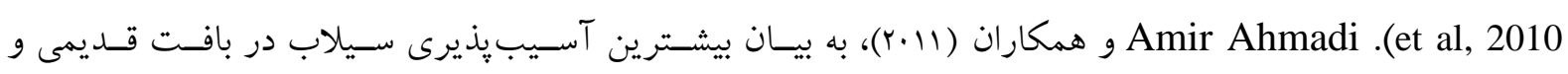
فرسودىى شهر سبزوار يرداختند (Amir Ahmadi et al, 2011). Rafiei. و همكـاران (rا.r) بـا استفاده از GIS و و

\footnotetext{
${ }^{1}$ Taichung
} 
فرايند تحليل سلسله مراتبى فازى، به پيهنهبندى خطر سيلاب شهرى و مطالهـى شـهر تهـران خرداختنـد. نتـايج ايسن

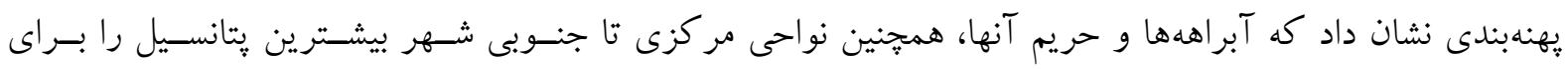

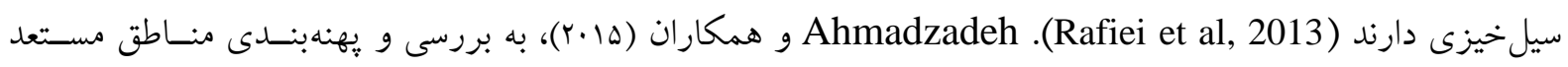

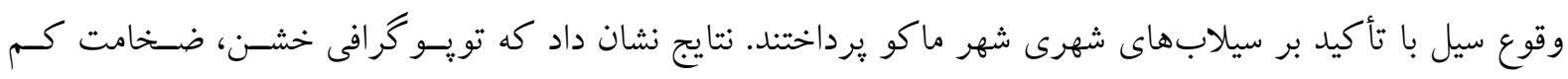
عناصر منفصل روى سنگ

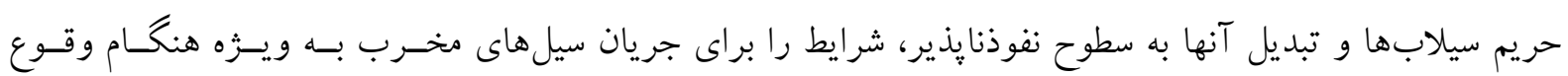
بارشهاى رگبارى در ماههـاى خشك سـال مهيـا مىسـازد (Ahmadzadeh et al, 2015) . Mahmoudzadeh و

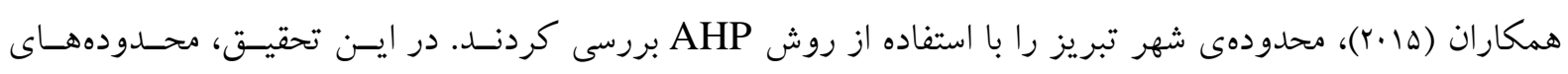

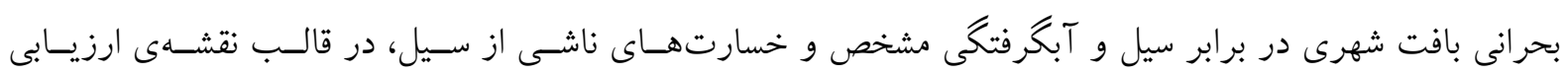

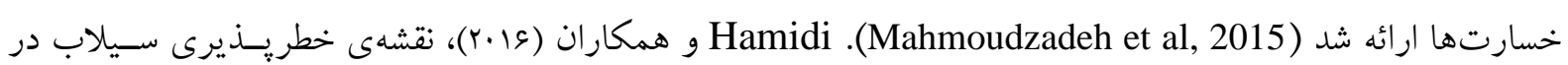

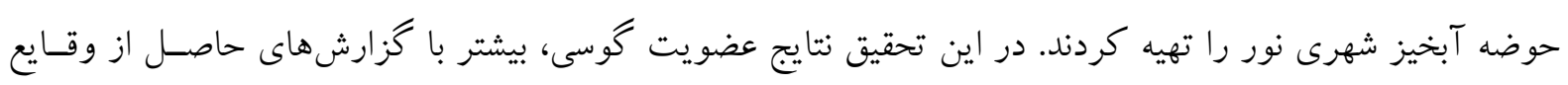

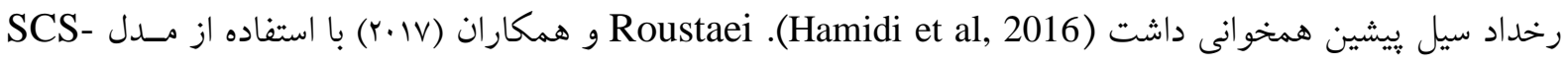
GIS/RS و به بررسى سيلاب حوضه آبخيز نكا رود يرداختند. نتايج تحقيق نشان داد كه بـهـ كاركيرى همزمـان

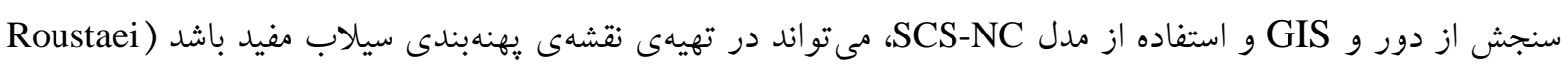

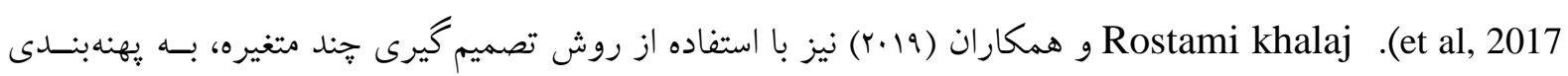

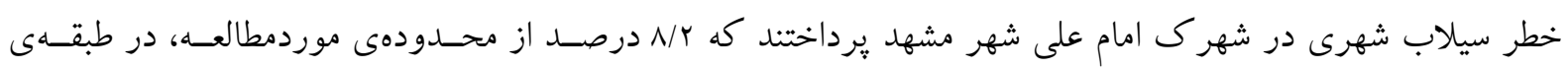
خيلى يرخطر قرار گرفت كه در نزديكى خروجى حوضه و اطراف كانال اصلى قرار داشت ( Rostami khalaj et al,

Abil

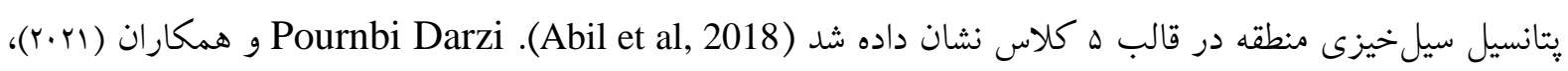
به يهنهبندى خطر سيل در حوضهى خشمه كيله در شهرستان تنكابن يرداختند. در ايسن تحقيـق از مــدل هيـدروليكى

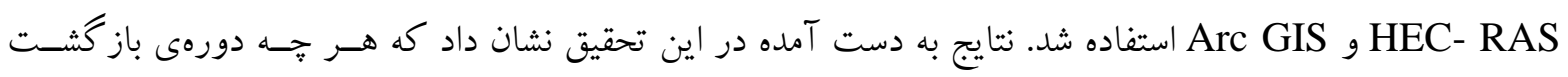

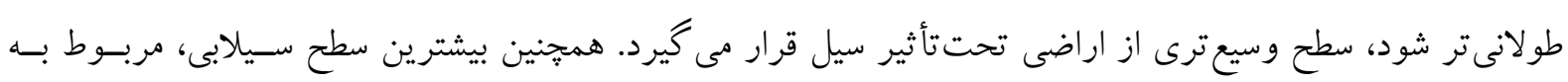

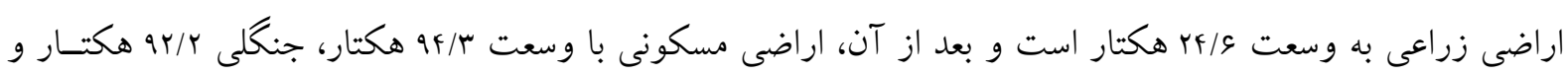
باغى ^/ • هكتار است (Pournbi Darzi et al, 2021).

\section{r ـ منطقهى موردمطالعه}

محدودهى مطالعاتى تحقيق حاضر شامل محدودهى شهرى و حاشيهى شهرى بندرعباس است. شهر بنـدرعباس در

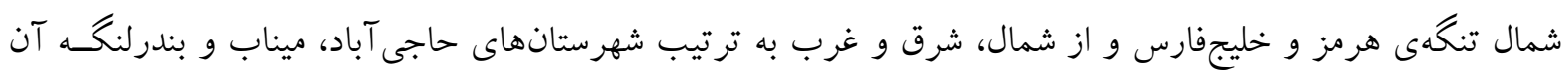

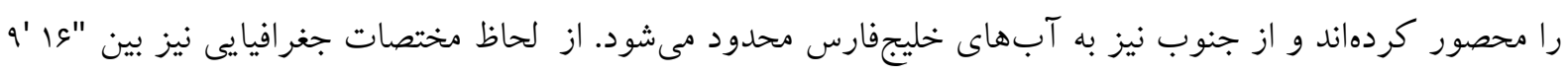

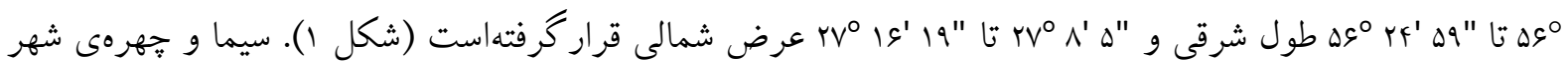
بندرعباس متأثر از عوامل طبيعى و محيطى و ساختهويرداختهى انسان است كه كسترش ساختارى آن در طول سـاحل 
و به شكل خطى است. محدودهى شهرى بندرعباس از نظر زئومورفولوزى، ارتفاع و شيب كمى دارد كه اين مسئله در

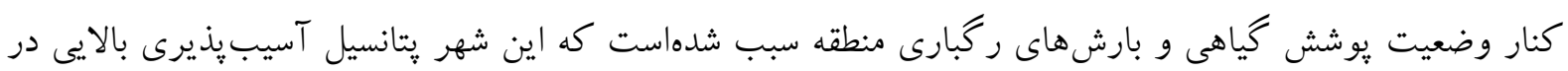
برابر خطر سيلاب داشته باشد.

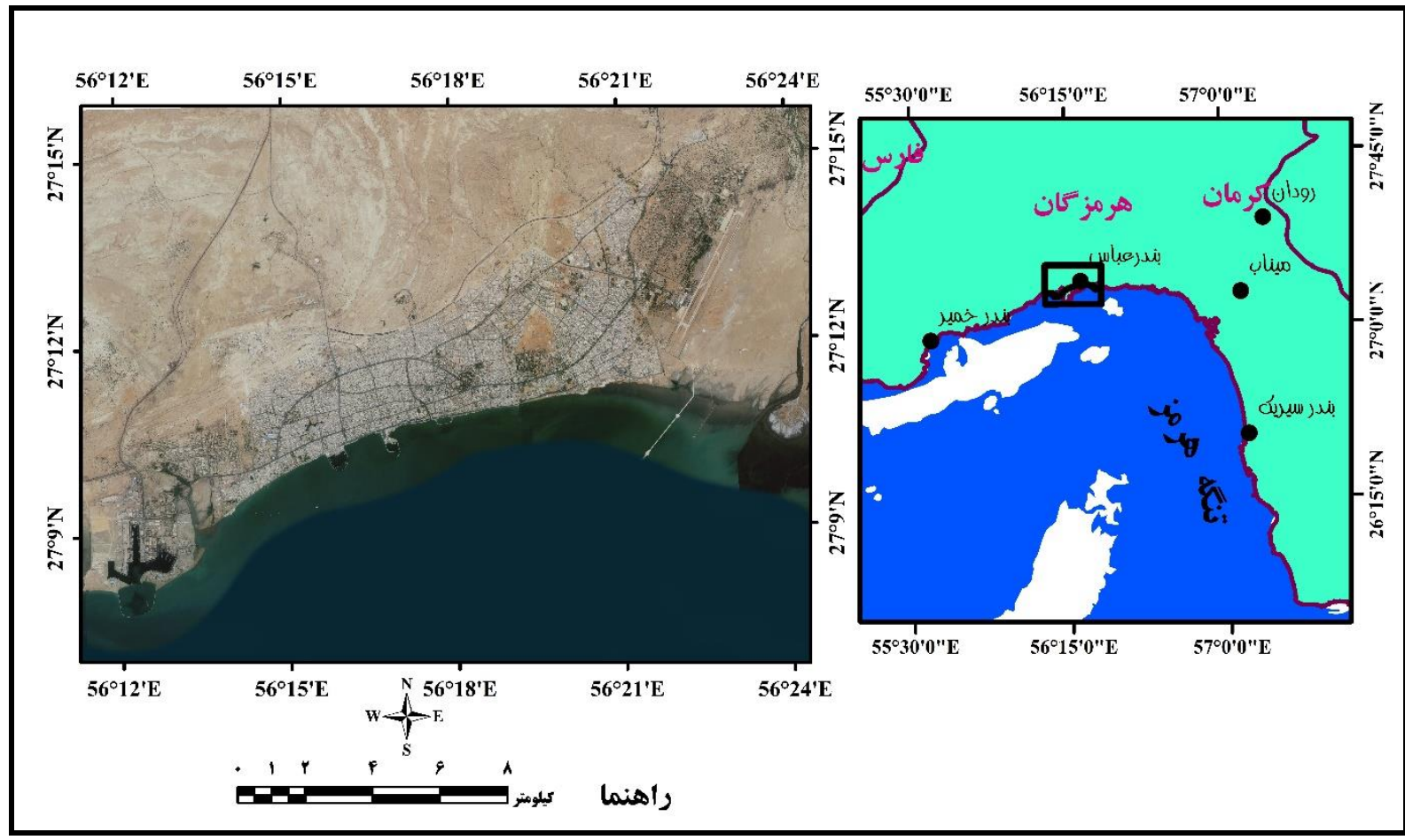

شكل ا: موقعيت منطقهى موردمطالعه'

rــ - مواد و روشها اين تحقيق بهمنظور دستيابى به اهداف موردنظر در دو مرحله انجام شد: در مرحلـهى اول، منـاطق مسـتعد وقــوع

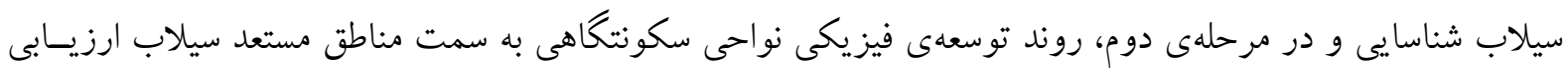

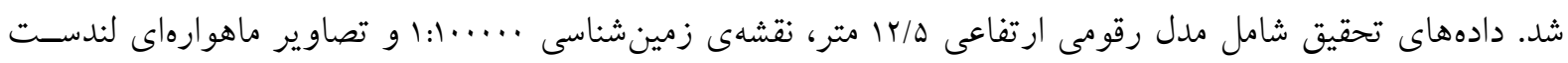

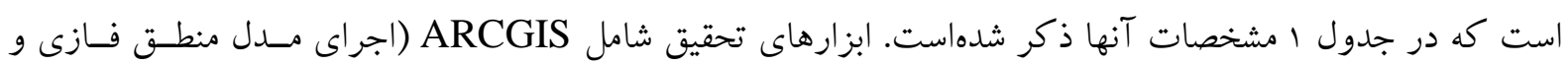

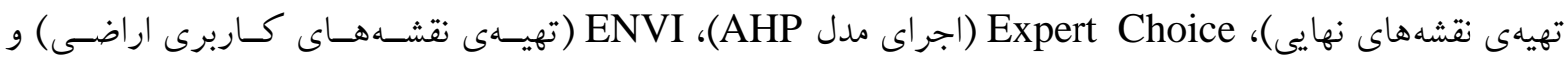

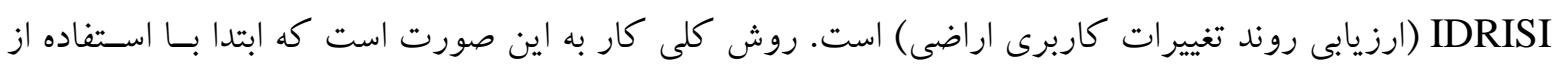

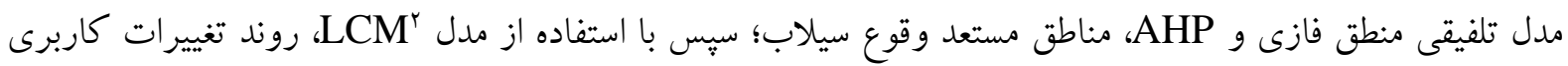

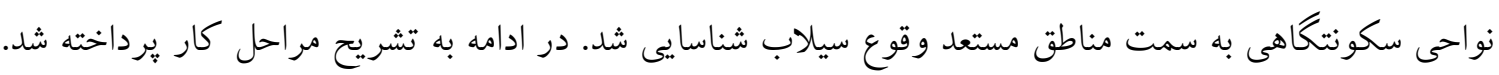


جدول ا: مشخصات تصاوير مورد استفاده

\begin{tabular}{|c|c|c|c|}
\hline سنجنده & ماهواره & تاريخ & رديف \\
\hline $\mathrm{TM}$ & لندست ه & $199 \cdot / \cdot 9 / 1 \mathrm{~V}$ & 1 \\
\hline TM & لندست ه & $r \ldots / \cdot s / l r$ & r \\
\hline ETM & لندست V & $r \cdot 1 \cdot / \cdot s / \cdot \Lambda$ & $r$ \\
\hline OLI & لندست & $r .19 / \cdot s / I V$ & $f$ \\
\hline
\end{tabular}

\section{ـ مرحلهى اول: (شناسايى مناطق مستعد وقوع سيلاب)}

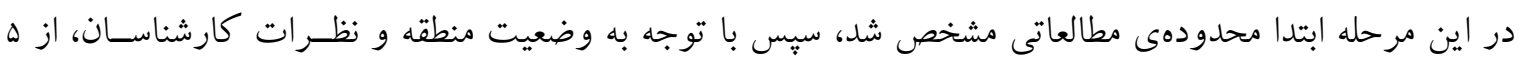

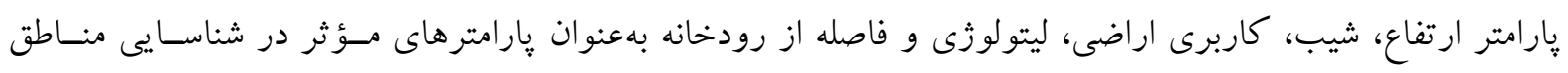

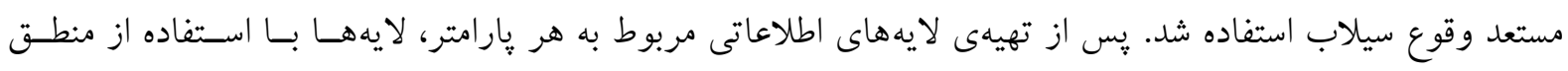

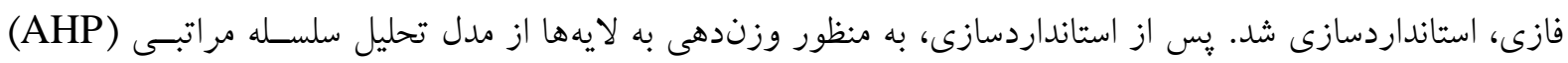

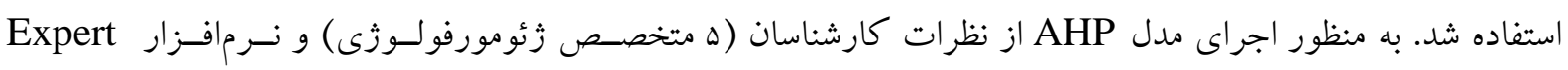
Choice استفاده شد. پِ از مشخص كردن وزن هر لايه (از طريق مقايسهى زوجى پارامترها)، در محيط ARCGIS

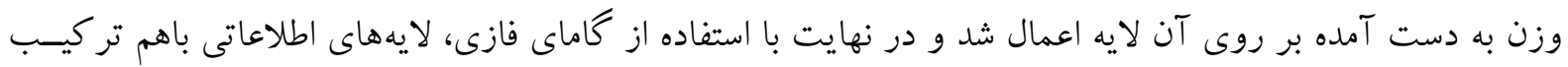
و نقشهى نهايى مناطق مستعد وقوع سيلاب تهيه شد.

\section{ـ مرحلهى دوم: (ارزيابى روند تو سعلى نواحى سكونتگاهى)}

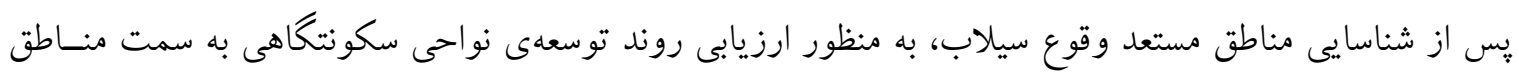

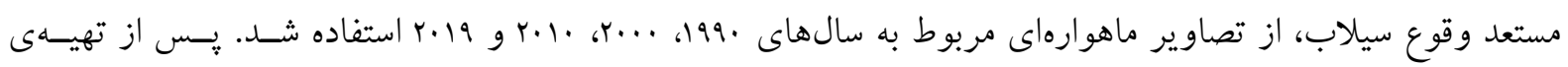

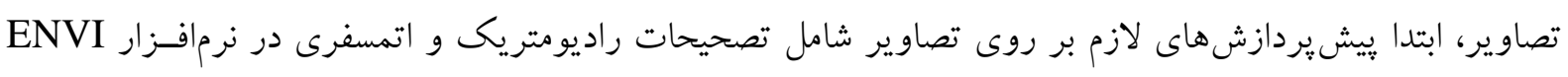

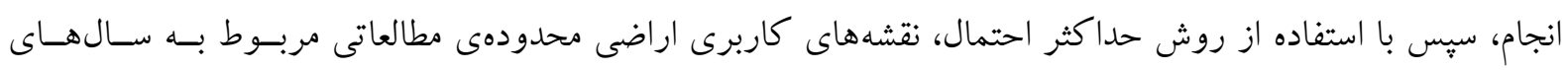

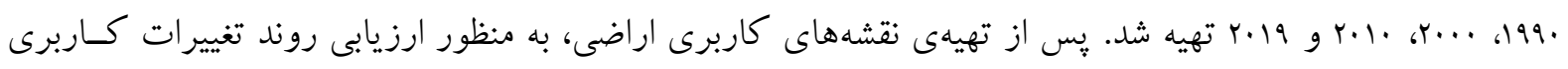

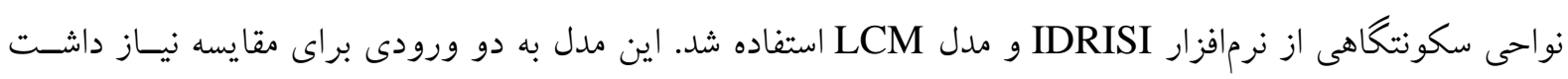

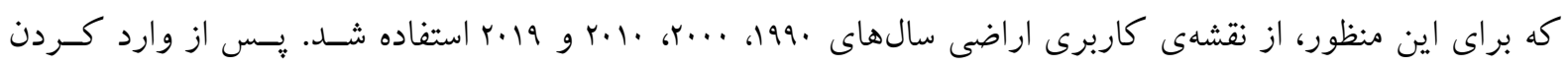
اطلاعات، كاهش و افزايش هر كدام از كاربرىها، ميزان تغيير هر كاربرى به كاربرى ديخر محاسبه شد. 
F - ب بحث و نتايج

شناسايى مناطق مستعد وقوع سيلاب: با توجه به اهميت شناسايى مناطق مستعد وقوع سيلاب، در اين پـزوهش بــا استفاده از ه هارامتر فاصله از رودخانه، ارتفاع، شيب، ليتولوزى و كاربرى اراضى، منـاطق مسـتعد وقـوع سـيلاب در

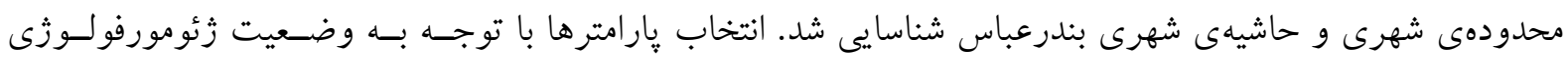
محدودهى مطالعاتى صورت گرفت. در ادامه به تشريح پارامترهاى مورد استفاده يرداخته شدهاست:

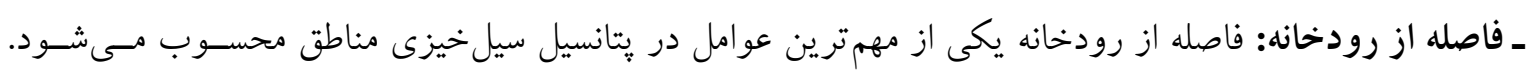
مناطقى كه در نزديكى جريان و رودخانه واقع شدهاند، بيشتر در معرض خطر سيل هستند. سرريز آب در زمهـان سئسيل

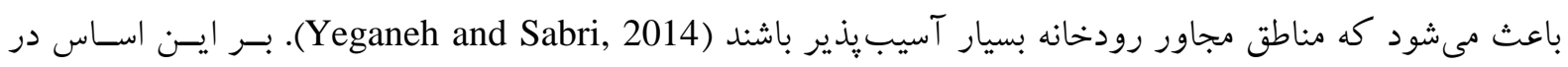

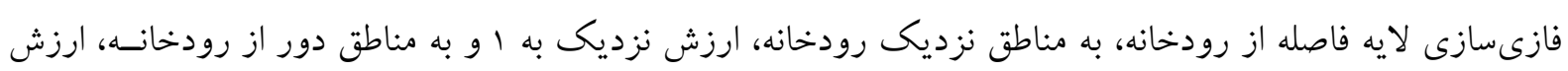
نزديك به صفر داده شد (شكل r).

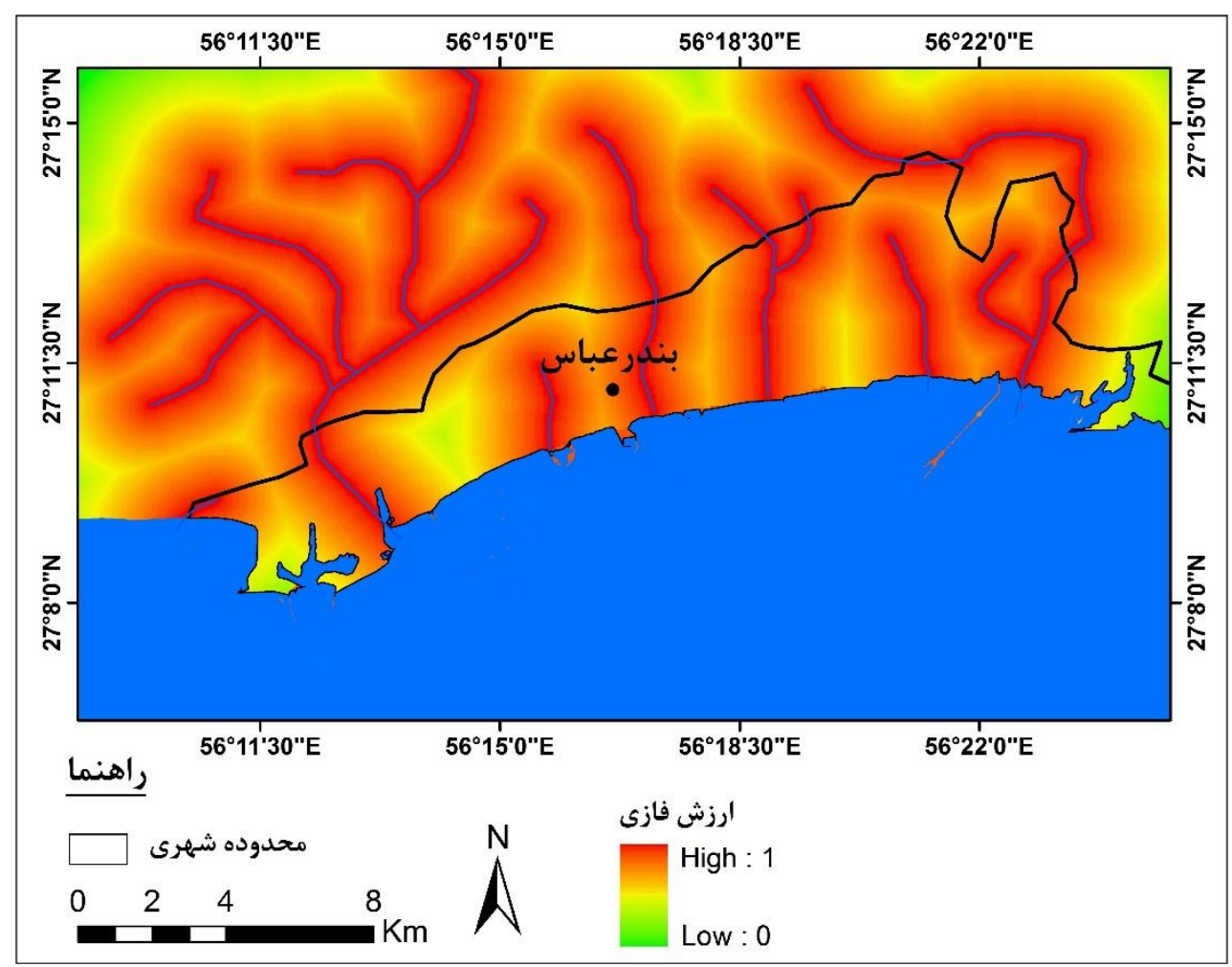

شكل r: نقشهى فازى شده لايه فاصله از رودخانه

ـ ارتفاع و شيب: ارتفاع، در مقدار بارندگى، دما، ميزان تبخير و تعرق، تشعشعات خورشيدى، تشـكيل و توسعهى

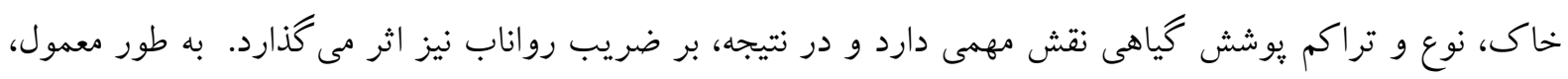

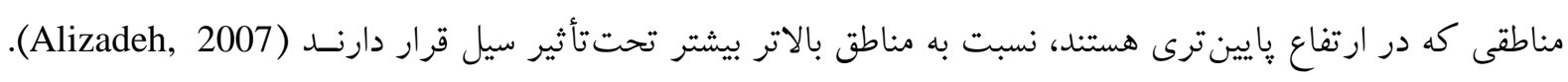

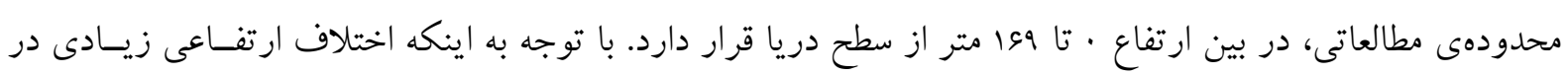
محدوده وجود ندارد، اختلاف زيادى در ميزان بارش و تبخير نيز ديده نمى شود، اما ايسن اخستلاف ارتفــاع در ميـزان 
يتانسيل سيلخيز منطقه بسيار تأثير گذار است؛ بهطورى كه مناطق داراى ارتفاع كم، پٍانسيل سيلخيزى بـالايى دارنـد.

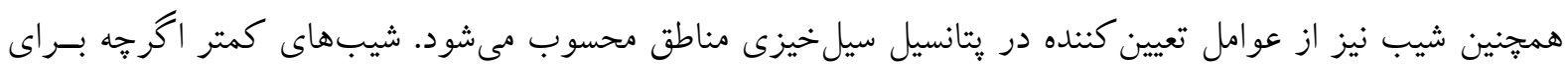

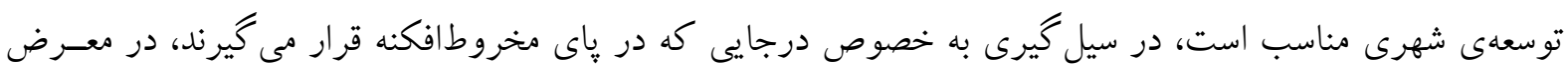
خطر بيشترى قرار دارند. در شيبهاى بالاتر، با حجم كمتر و جريانهاى سريعترى از سيلاب روبــرو هسـتيم. هرجـهـ

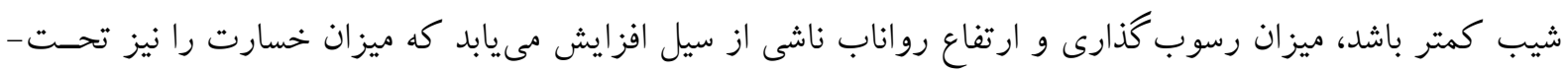
تأثير قرار مىدهد (Abroush, 2016). با توجه به موارد مذكور، در فازىسازى لايههاى ارتفاع و شيب، به مناطقى كه دئ ارتفاع و شيب كمترى دارند، ارزش نزديك به ا و به مناطقى كه ارتفاع و شيب بيشترى دارند، ارزش نزديكى به صفر داده شدهاست (شكل r) (r).

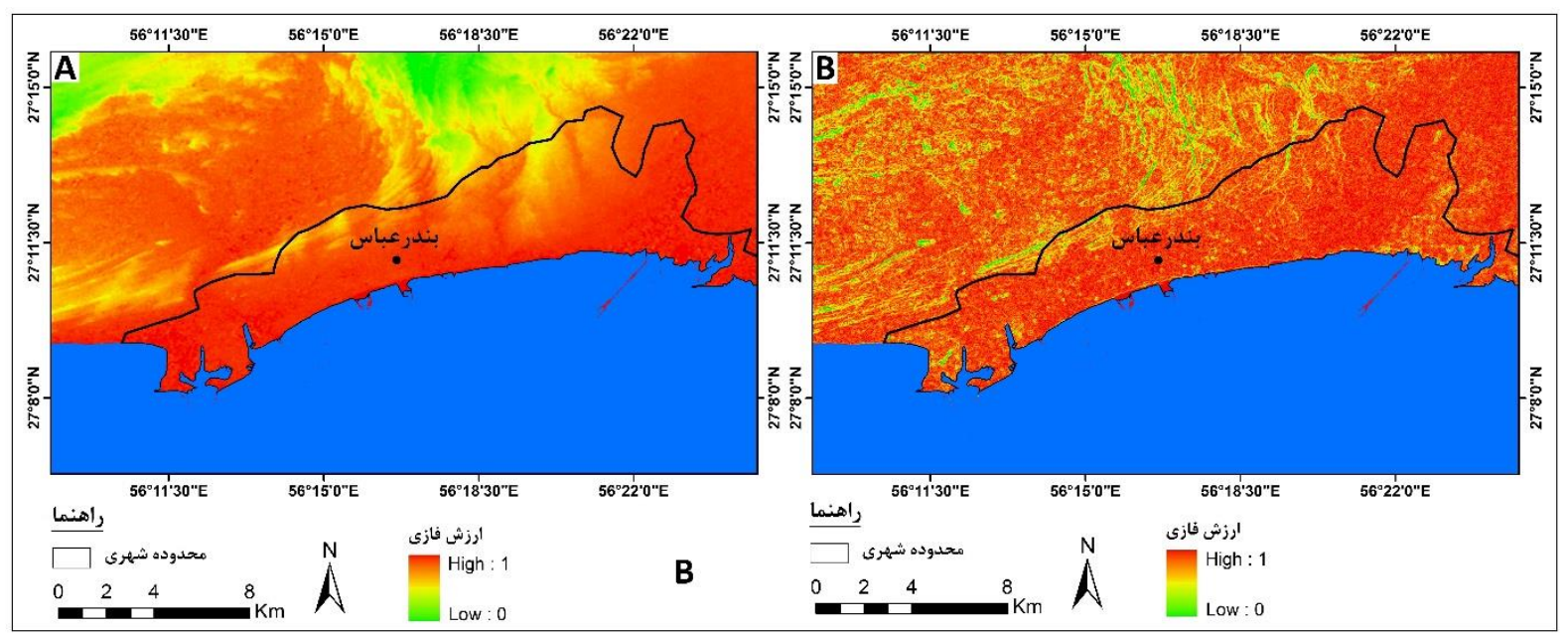

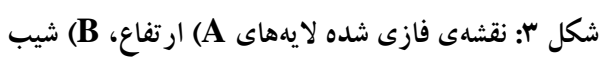

ـ ليتولوزى و كاربرى اراضى: نوع سنگ و يوشش خاك، ظرفيت نفوذ را تحت تأثير قرار مىدهد. خاك يا سنگ قابل نفوذ، شرايط نفوذ آب به داخل زمين را فراهم مى كند و تخليهى آن را به درون آبراهلى اصلى به تأخير مى اندازد

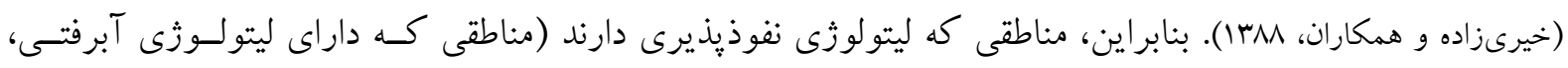

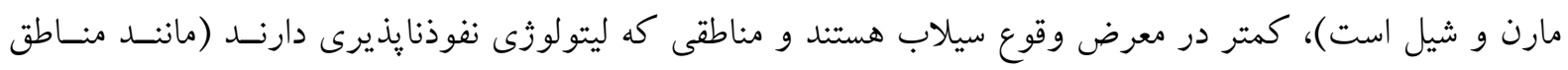
داراى ليتولوذى بازالت و آندزيت)، بيشتر در معرض وقوع سيلاب هستند. نوع كاربرى اراضى نيز در يتانسيل سـيل -

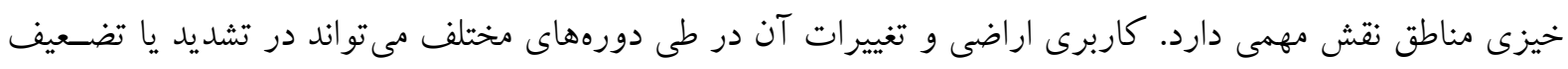
سيلاب نقش حياتى داشته باشد. حوادث زمين تحت تأثير نوع استفاده از زمين و كاربرى زمين است. سطوح نفوذنايذير

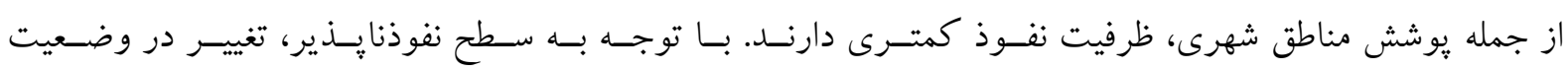

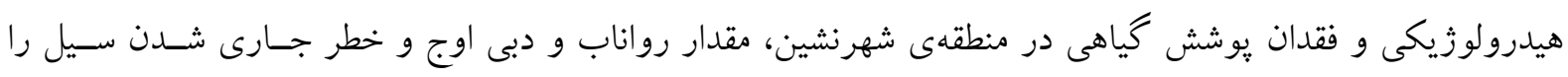

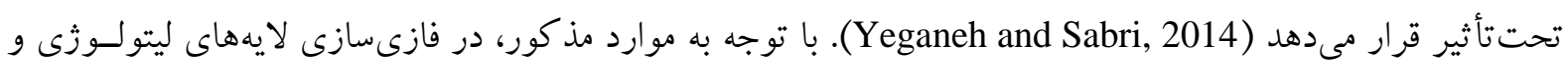

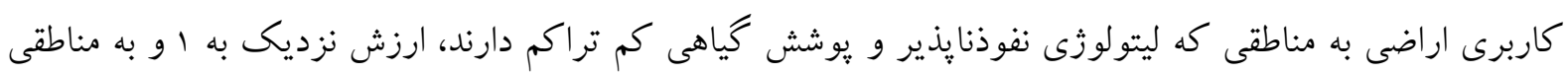

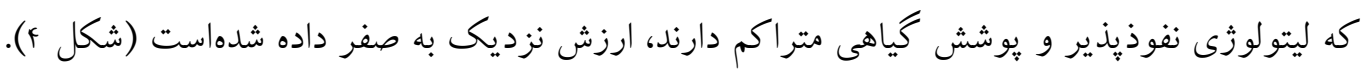




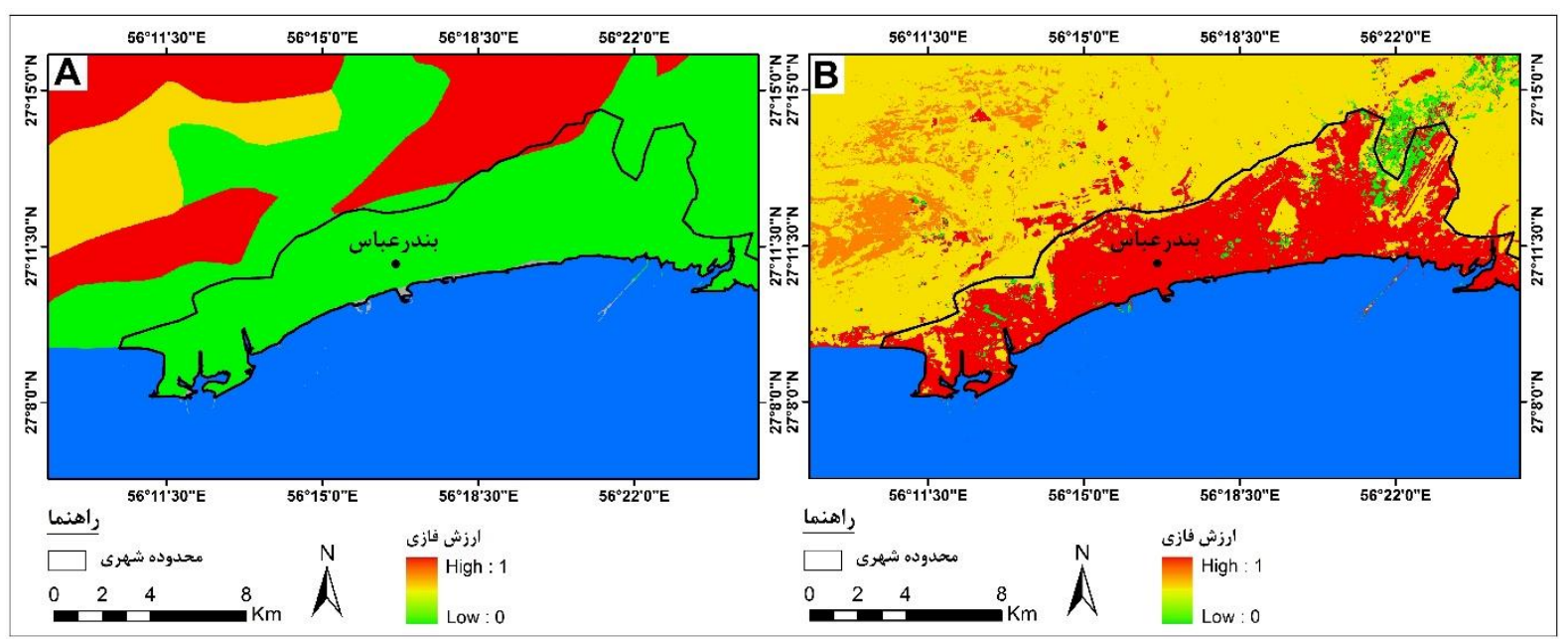

شكل †: نقشهى فازى شده لايههاى A) ليتولوزى، B (B) كاربرى اراضى

ـ وزندهى و تلفيق لايههاى اطلاعاتى: با توجه به اينكه ارزش و اهميت لايههاى اطلاعاتى يكسان نيست پسس از

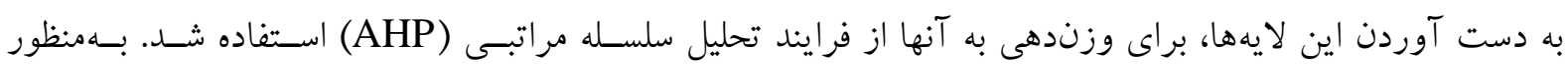

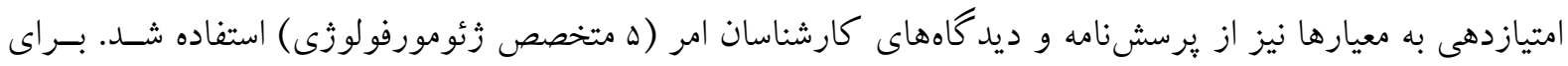
اجراى محاسبات از نرمافزار expert choice استفاده و يس از به دست آوردن وزنهاى نهايى هر كـــام از معيارهــا ARCGIS بر روى دادهها اعمال شد. يس از وزندهى به لايه هاى اطلاعاتى، وزن به دست آهده

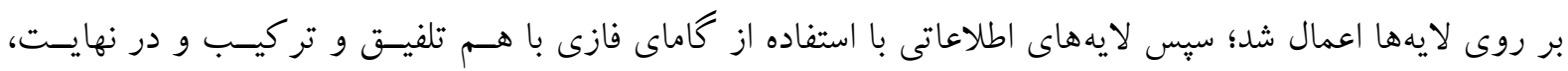
نقشهى نهايى مناطق مستعد وقوع سيلاب تهيه شد (شكل ع).

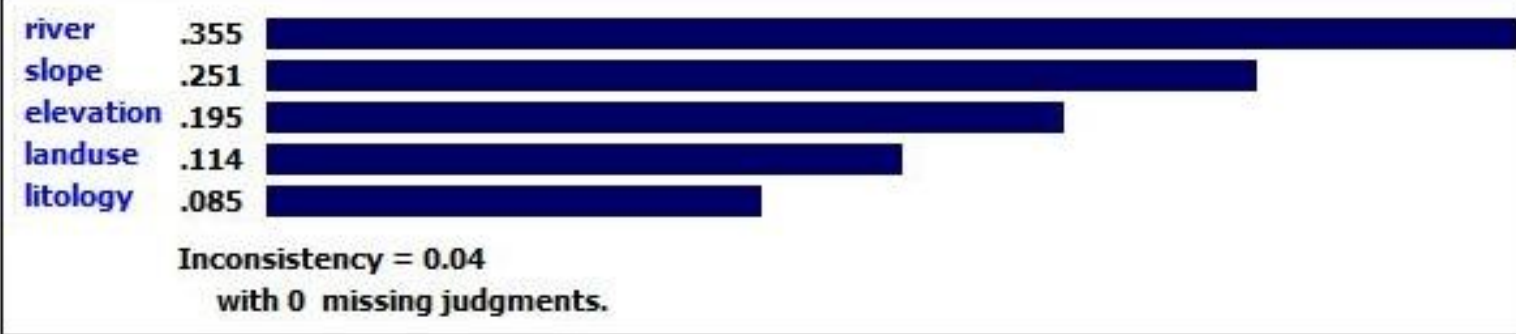

شكل ه: ارزش گذارى لايههاى اطلاعاتى بر اساس مدل AHP 


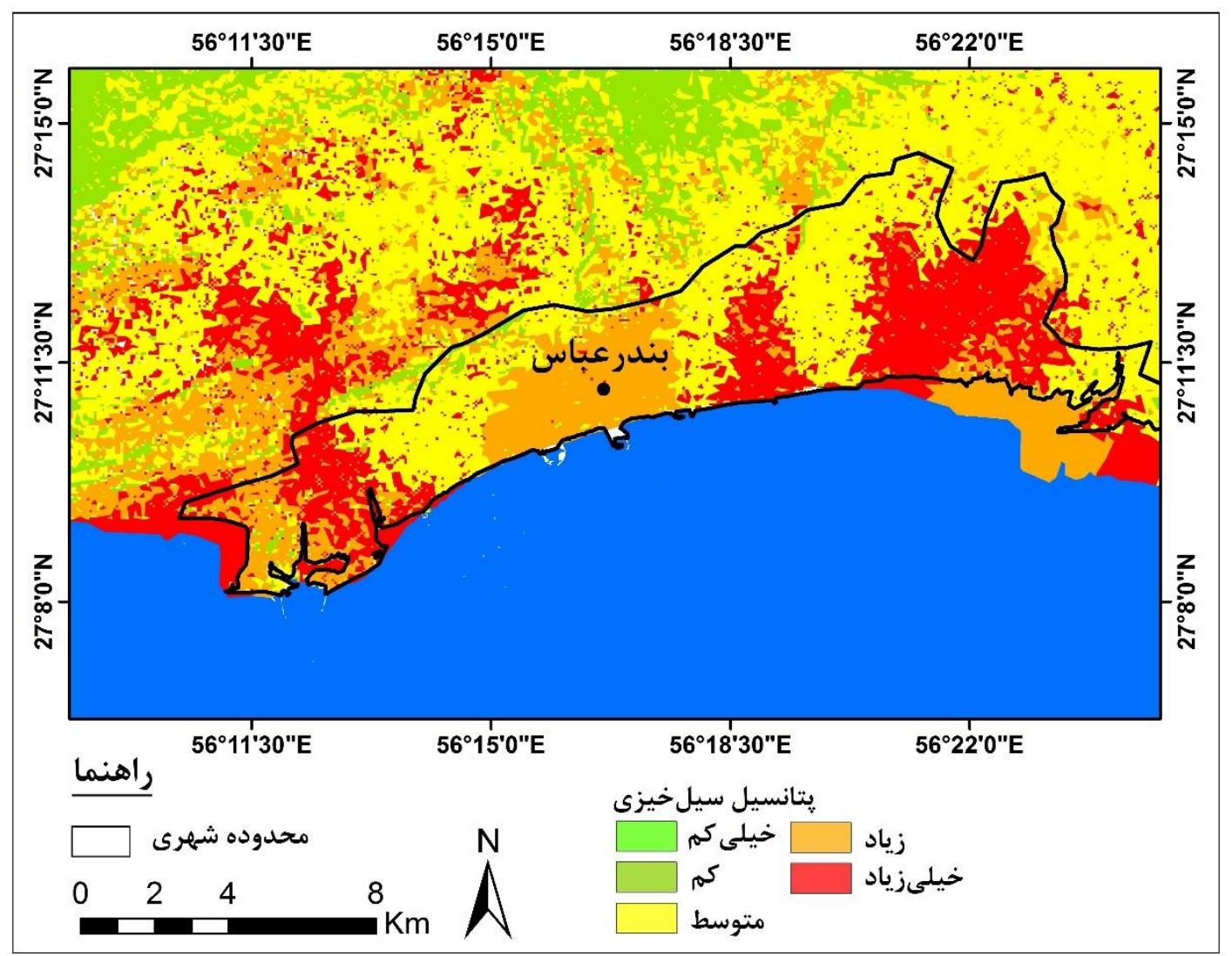

شكل ع: نقشهى نهايى مناطق مستعد وقوع سيلاب در محدودمى مطالعاتى

ارزيابى نتايج نهايى مناطق مستعد وقوع سيلاب (جدول r) بيـانكر ايسن اسـت كـهـ بخـش زيـادى از محسـودهى

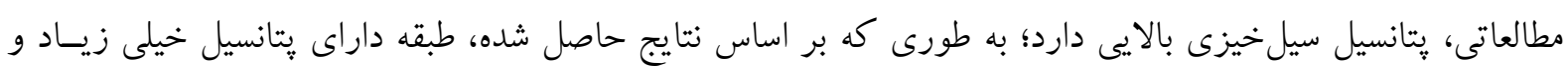

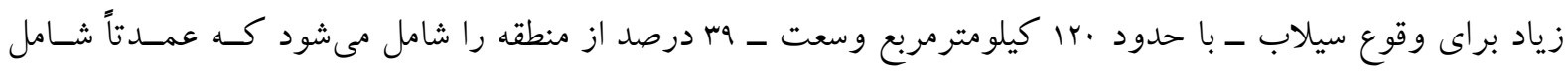
مناطق غربى و شرقى محدودهى شهرى بندرعباس است كه به دليل نزديكى به رودخانه، ارتفاع و شيب كم، يتانسـيل سيلخيزى بالايى دارد.

جدول r: مساحت و درصد مساحت طبقات مستعد وقوع سيلاب

\begin{tabular}{|c|c|c|c|c|c|}
\hline خيلى زياد & زياد & متو سط & 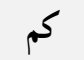 & خيلى كم & يتانسيل سيلخيزى \\
\hline 09 & s $/ f$ & $\mid f \Delta / \Lambda$ & $F 1 / 1$ & 1 & مساحت \\
\hline $19 / 1$ & $19 / 9$ & $\mathrm{FV} / \mathrm{r}$ & $\mid r / \mu$ & $\cdot / \mu$ & درصد مساحت \\
\hline
\end{tabular}

ارزيابى روند تغييرات كاربرى اراضى: در اين بزوهش به منظور بررسى تغييرات كاربرى اراضى و روند توسـعه

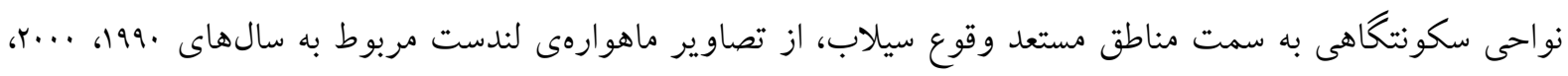

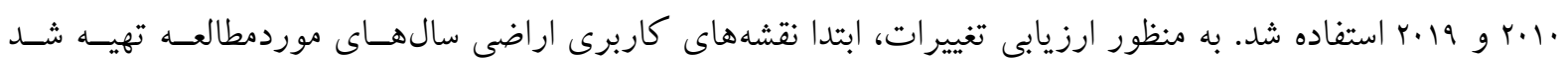

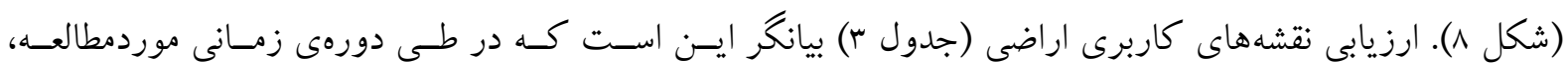

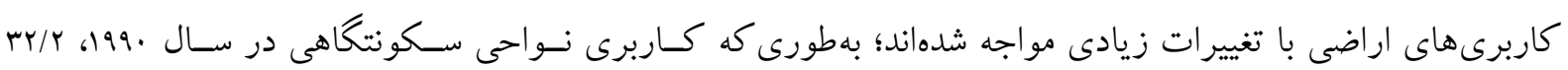




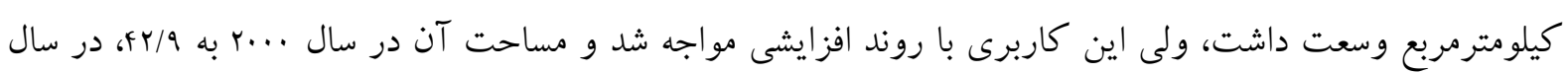

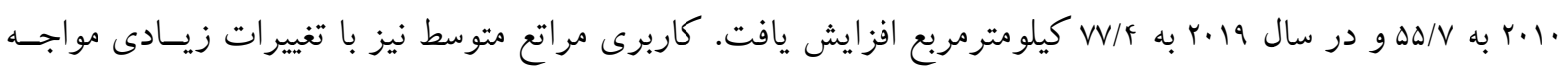

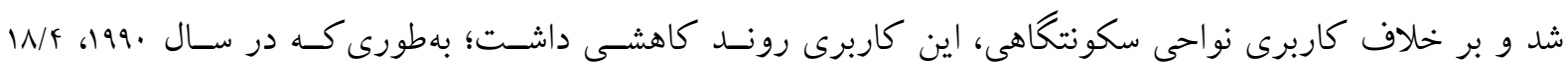

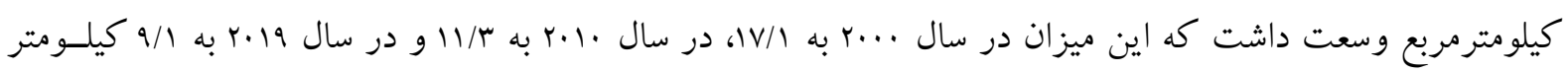

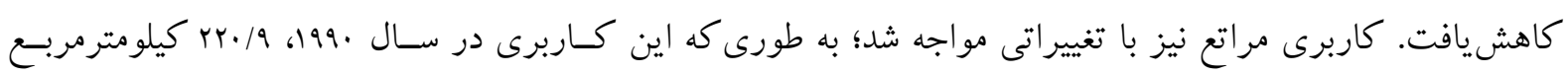

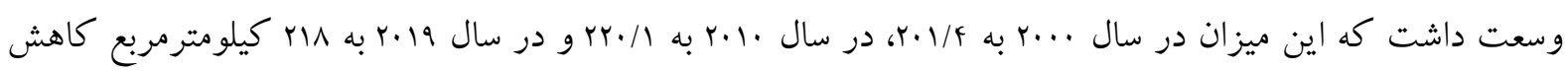

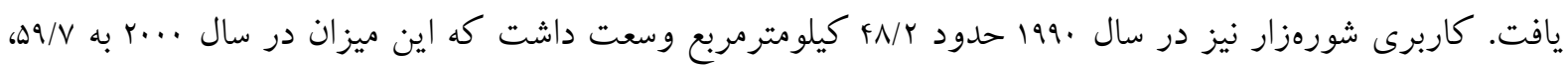

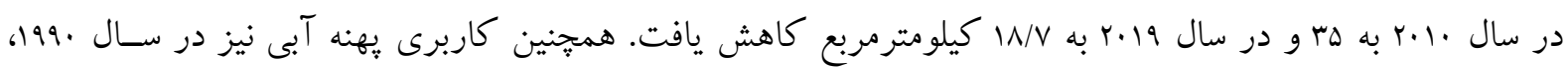

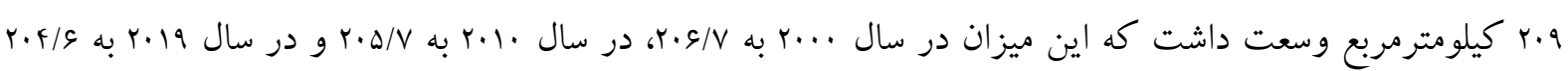

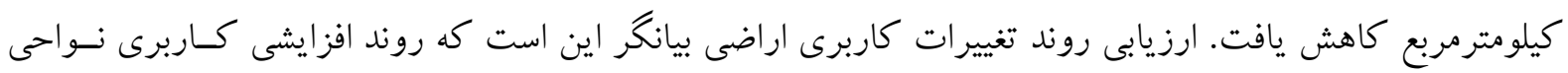

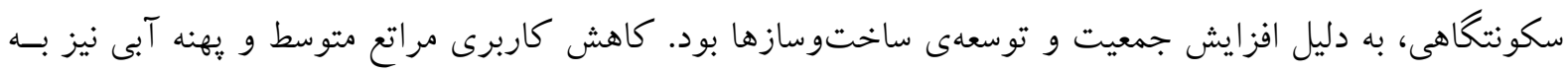

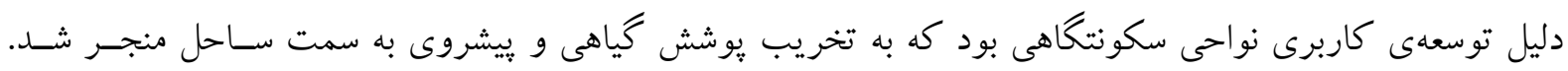

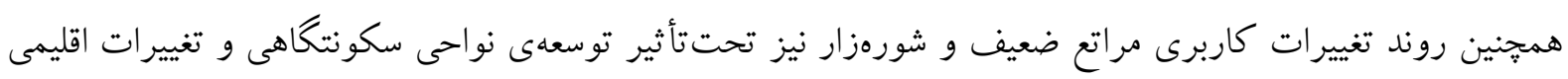
صورت گرفت

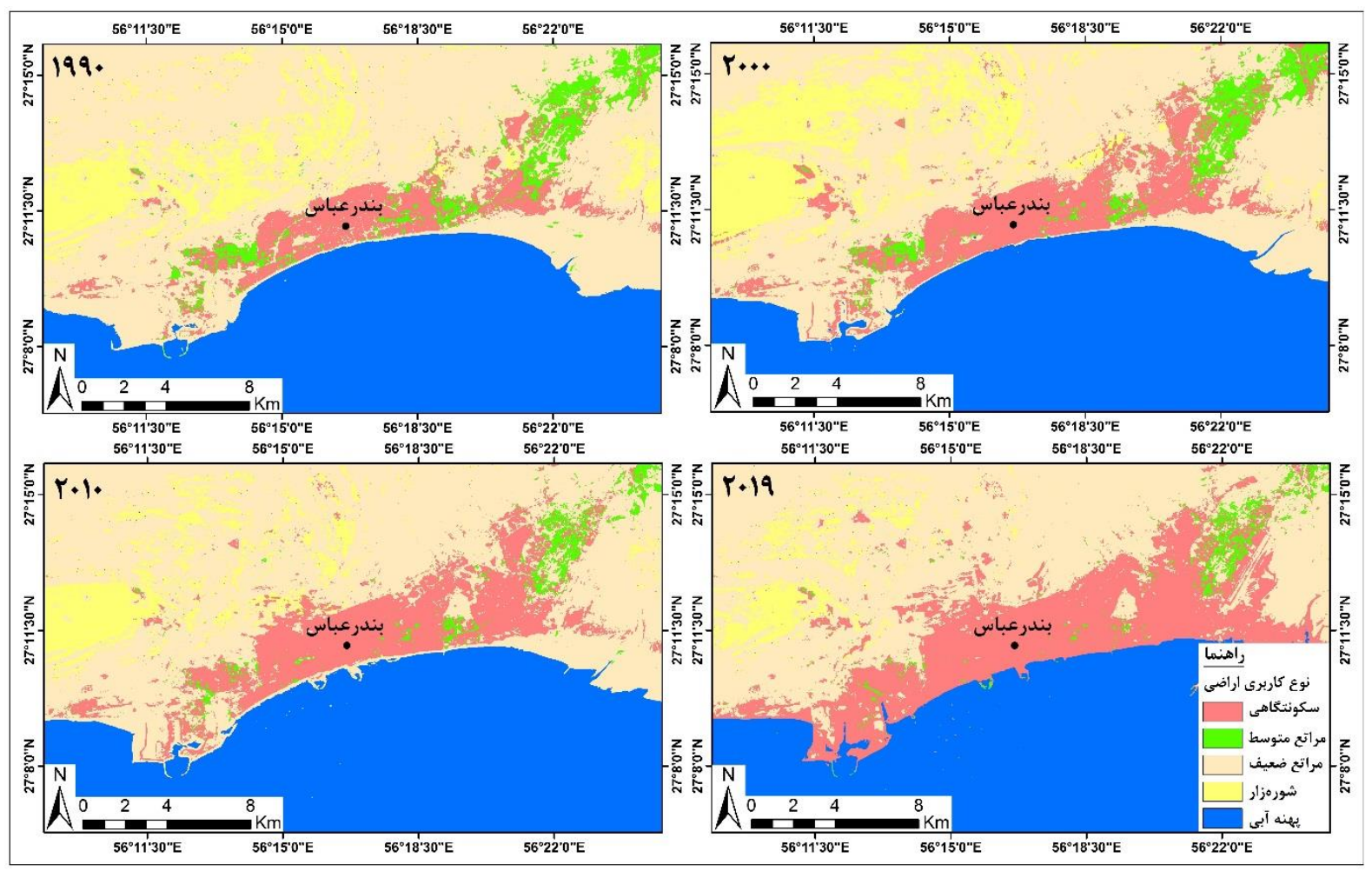

شكل ^: نقشهاى كاربرى اراضى محدودهى مطالعاتى 
جدول ץ: مساحت كاربرىهاى اراضى (كيلومترمربع)

\begin{tabular}{|c|c|c|c|c|c|}
\hline يهنه آبى & شورهزار & مر اتع ضعيف & مراتع متوسط & سكونتخاهى & سال \\
\hline$r \cdot \Lambda$ & $F N / T$ & $r r \cdot / 9$ & $\mid N / F$ & $r Y / r$ & 199. \\
\hline$r \cdot G / V$ & $\Delta 9 / V$ & $r \cdot 1 / f$ & $1 \mathrm{~V} / \mathrm{I}$ & $F r / q$ & $r \ldots$ \\
\hline$r \cdot \Delta / V$ & ra & $r r \cdot / l$ & $11 / \mu$ & $\Delta \Delta / V$ & $r \cdot 1$. \\
\hline$r \cdot r / s$ & $1 N / V$ & 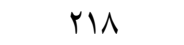 & $9 / 1$ & $\mathrm{~V} / \mathrm{f}$ & $r .19$ \\
\hline
\end{tabular}

ارزيابى روند تغييرات كاربرى اراضى، بيانكر رشد قابل توجه نواحى سكونتگاهى است. در اين يزوهش به منظــور

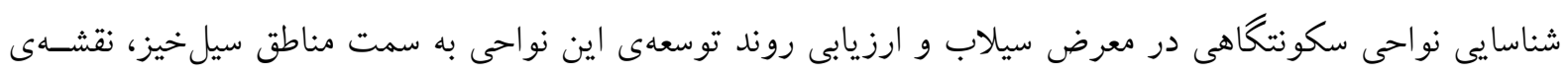

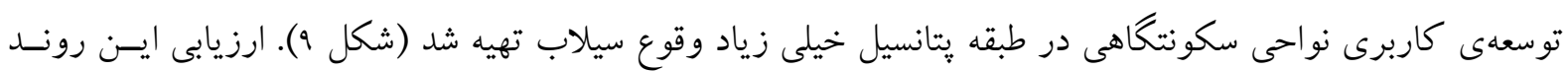

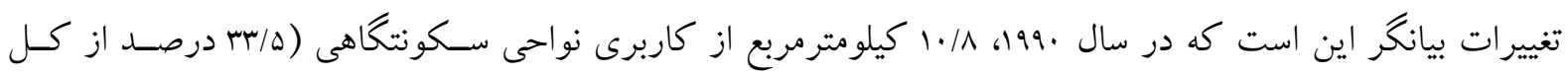

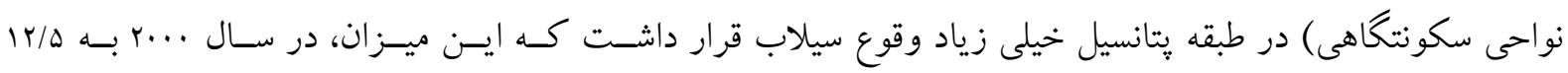

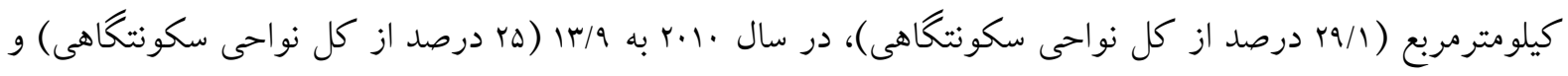

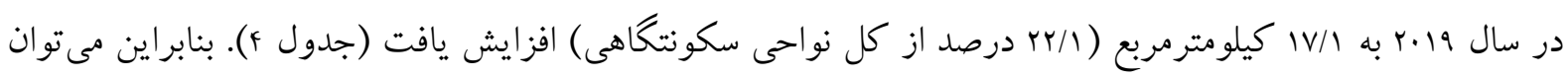
كفت كه در طى سالهاى اخير، بخش زيادى از نواحى سكونتخاهى به سمت مناطق سيلخيز حركت كردهاست.

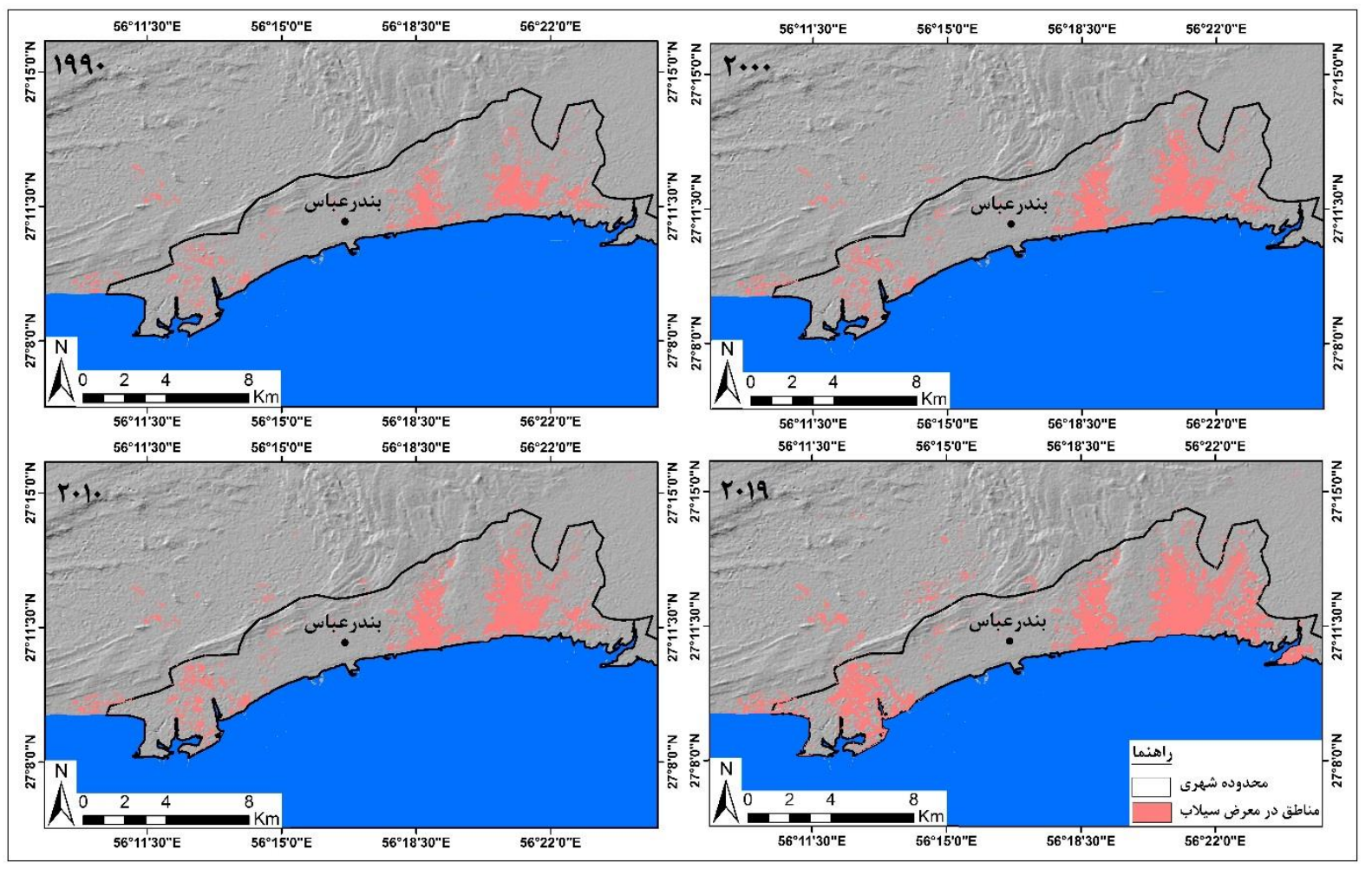

شكل 9: نقشهى توسعلى كاربرى نواحى سكونتكاهى در طبقه يتانسيل خيلى زياد وقوع سيلاب 
جدول f: مساحت مناطق در معرض سيلاب در طى سالهاى موردمطالعه (كيلومترمربع)

\begin{tabular}{|c|c|c|c|c|}
\hline$r \cdot 19$ & $r \cdot 1$. & $r \ldots$ & 199. & 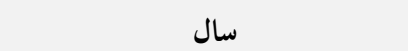 \\
\hline $\mid V / 1$ & $11 \% / 9$ & $\mid r / D$ & $1 \cdot / 1$ & 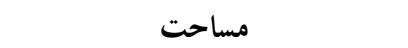 \\
\hline$r r / l$ & ra & $r q / 1$ & 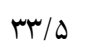 & درصد از كل مساحت سكونتخاهها \\
\hline
\end{tabular}

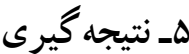

سيلابها يكى از مهمترين خطراتى است كه همواره خسارتهاى جانى و مالى زيادى به همراه داشتهاست. مناطق

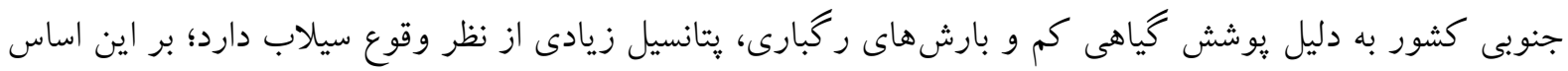
در اين تحقيق، وضعيت سيلخيزى شهر بندرعباس ارزيابى شد. به دليل نتايج قابلقبول تحقيقات ييشـين در زمينسهى

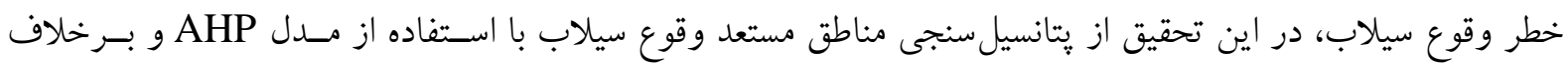
بسيارى از تحقيقات ييشين، از روند توسعهى نواحى سكونتكاهى به سمت مناطق سيلخيز با مدل LCM استفاده شد تا

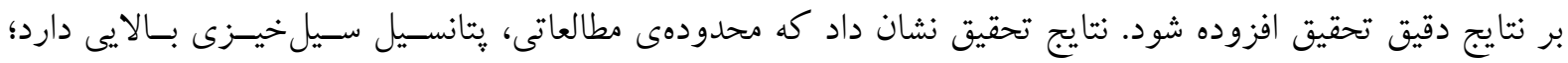

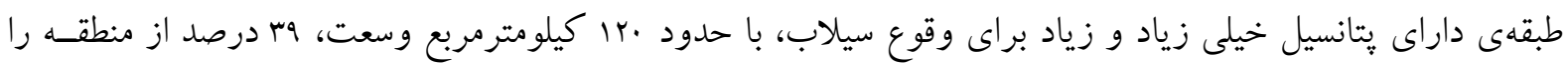
شامل مى شود كه عمدتاً شامل مناطق غربى و شرقى محدودهى شهرى بندرعباس است. اين مناطق به دليل نزديكى بــــ

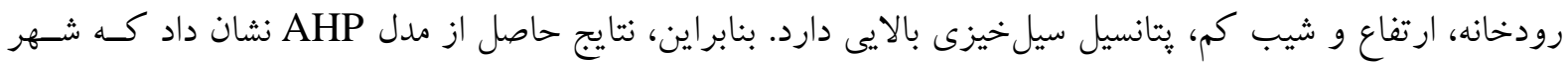

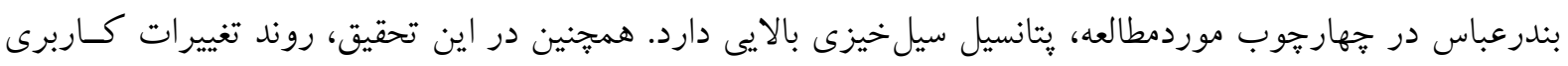

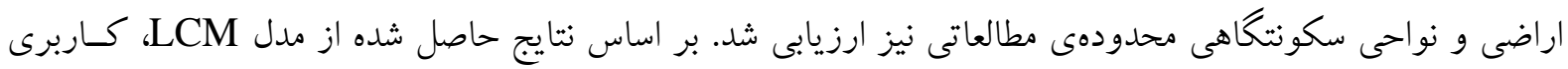

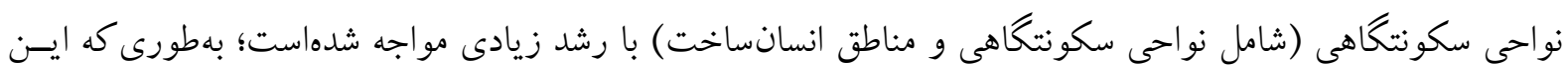

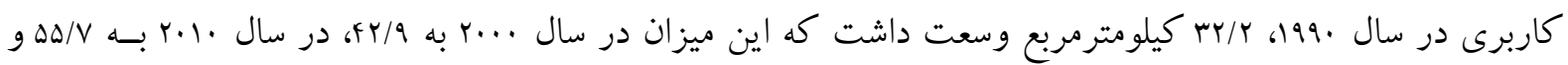

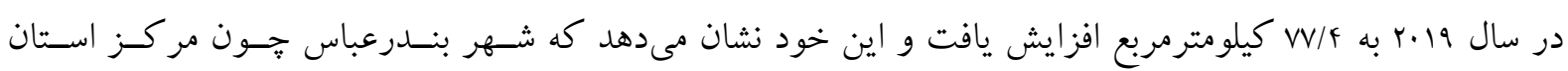

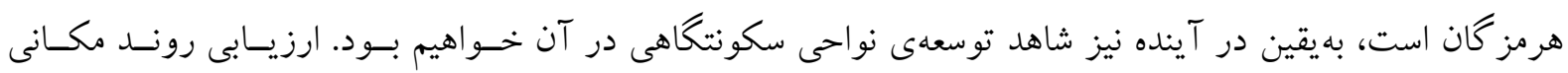

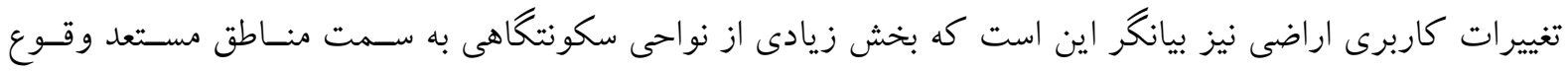

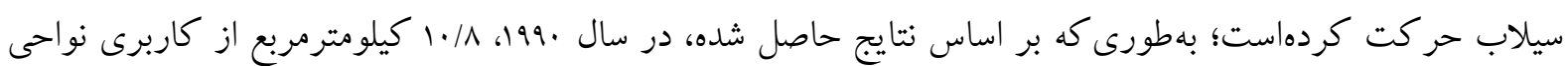

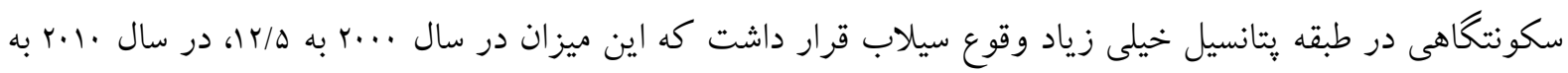

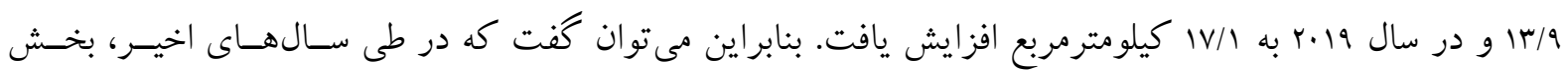

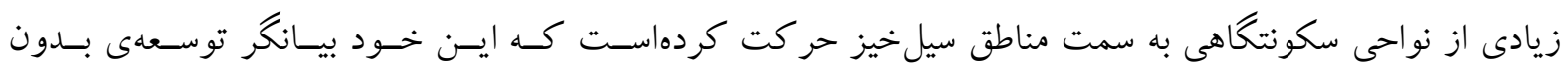

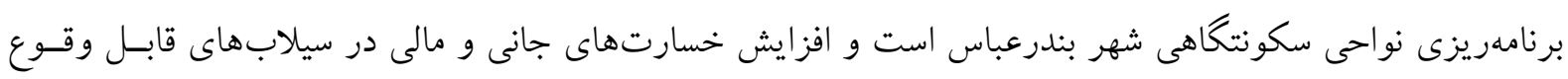

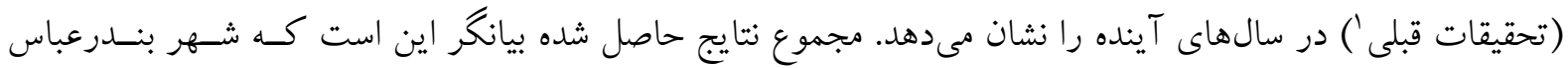

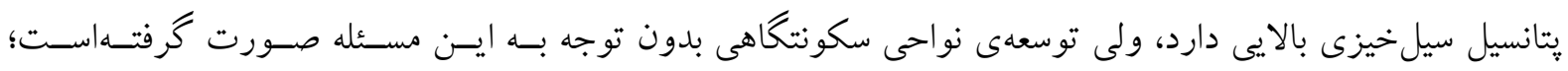

\footnotetext{
${ }^{1}$ Karam and derakhshan, 2012
} 


\section{بنابراين، لازم است بر روند توسعهى نواحى سكونتخاهى و هدايت آنها به سمت منــاطق كـمخطـر نظـارت بيشـترى صورت كيرد. \\ منابع}

1. Abil, A. B.; Tavousi, T.; \& M. Khosravi, 2019. Analysis of potential areas at risk of urban floods Case Study of Zahedan, Geography and Development, 54, 91-106. (in Persian).

2. Abroush, Z., 2016. Flood risk zoning in Pardisan area of Qom with the approach of locating rescue bases, M.Sc. Thesis, University of Tehran, Faculty of Geography. (in Persian).

3. Ahmadzadeh, H.; Saeedabadi, S.; \& E, Nouri, 2015. Investigation and zoning of flood prone areas up to and including urban floods (Case study: Mako city), Hydrogeomorphology, 2, 1-23. (in Persian).

4. Amira Ahmadi, A.; Keramati, S.; \& T, Ahmadi, 2011. Flood risk microzonation within the city of Neishabour for urban development, Urban Research and Planning, 2(7), 91-110. (in Persian).

5. Alizadeh, A., 2007. Principles of Applied Hydrology, Imam Reza University Press, Mashhad, 20th edition. (in Persian).

6. Al-ghamdi, K. A., 2012. GIS evaluation of urban growth and flood hazards: a case study of Makkah city, Saudi Arabia, Knowing to manage the territory, protect the environment, evaluate the cultural heritage, Rome, Italy, PP, 6-10.

7. Bhattacharya, N., 2010. Flood risk assessment in Barcelona, France. The Netherlands: International institute for geo-information science and earth observation Enscheda (ITC).

8. Chen, Y. R.; Yeh, C. H.; \& B. Yu, 2011. Integrated application of the analytic hierarchy process and the geographic information system for flood risk assessment and flood plain management in Taiwan, Natural hazards, 59(3), 1261 -1276.

9. Chen, J., 2009. A GIS-based model for urban flood inundation, Hydrology, 373, 184-192.

10. Dung, N.; Quoc Long, N.; Tran An, D.; \& D. Tuyet Minh, 2021. Multi-geospatial flood hazard modelling for a large and complex river basin with data sparsity: a case study of the Lam River Basin, Vietnam, Earth Systems and Environment, V 20.

11. Eshghizadeh, M.; Nader, N.; \& A. Sepehri, 2010. Evaluation of suitable runoff collection areas in the watershed system, Journal of Soil and Water Conservation Research, 2, 36-45. (in Persian).

12. Fernández, D., \& M. Lutz., (2010). Urban flood hazard zoning in Tucumán Province, Argentina, using GIS and multicriteria decision analysis. Engineering Geology. 111 (1), 90-98. 13. Ganjaeian, H., 2020. Geomorphological hazards of urban areas, study methods and control tools, Select Publishing, page 144. (in Persian).

14. Ghorbanzadeh, M.; Azarakhshi, M.; Masaedi, A.; Rostami, K.; \& h, Mohammad, 2017. Evaluation of the efficiency of AHP method in determining areas prone to urban flood risk (Case study: Central part of Torbat-e Heydariyeh), Natural Geography Research, 4, 645-656. (in Persian).

15. Hamidi, N.; Vafakhah, M.; \& A, Najafi, 2016. Preparation of flood risk map in Noor urban watershed using hierarchical analysis and fuzzy logic, Watershed Management Research Journal, 14, 11-19. (in Persian).

16. Karam, A., \& F. Derakhshan., (2012). Flood zonation, flood estimation and evaluation of surface water drainage canals in urban basins.

17. Khairizadeh, A.; Maleki, G.; \& H, Amunia, 2009. Zoning the potential for flood risk in the Mardagh Chay basin or using the ANP model, Journal of Quantitative Geomorphological Research, 3, 59-36. (in Persian).

18. Mahmoudzadeh, H.; Emami Kia, V.; \& A. A. Rasouli, 2015. Flood risk zoning in Tabriz using AHP method, Geographical Research Quarterly, 116, 167-180. ( in Persian). 
19. Negargh, H., \& M. Daraei., (2009). Expansion of Saqez city and its effects on flooding in Cham Saqez catchment. Journal of Geographical Sciences Research. 14,145-165. (in Persian). 20. Pournbi Darzi, S.; Wafakhah, M.; \& M. R. Rajabi, 1400. Flood Risk Zoning Using HECRAS and Arc GIS Hydraulic Model (Case Study: Cheshmeh Kileh Watershed, Tonekabon), Journal of Environmental Hazards, 10 (27), 25-36 . (in Persian).

21. Rostami, Kh.; Mohammad, D.; \& T. Teymourian, 2019. Urban flood risk zoning using multivariate decision making method (Case study: Imam Ali town, Mashhad), Environmental Science and Technology, 11, 173-185. (in Persian).

22. Rafiei, Y.; Salehi, I.; Farzad Behtash, M.; \&. M. T. Aghababaei, 2013. Urban flood risk zoning using GIS and fuzzy hierarchical analysis process (Case study: Tehran), Environmental Studies, 3, 179-188. (in Persian).

23. Roustaei, Sh.; Mousavi, R.; \& Gh. Alizadeh Gorji, 2017. Preparation of flood zoning map of Nekarood basin using SCS-CN and GIS / RS models, Quantitative Geomorphological Research, 1, 108-118. (in Persian).

24. Rahmati, O.; Zeinivand, H.; \& M. Besharat, 2016. Flood hazard zoning in Yasooj region, Iran, using GIS and multi-criteria decision analysis, Geomatics, Natural Hazards and Risk, 17(3), 1000-1017.

25. Sepehr, A., \& R. Kavian., (2014). Classification of tolerance of urban metropolitan areas of Mashhad to environmental hazards using linear programming of SIMUS periodic interaction. geography and environmental hazards. 9, 125-141. ( in Persian).

26. sheghpoor, S. E., \& B. Ajdari., (2011). A Case Study on Seasonal Floods in Iran, Watershed of Ghotour Chai Basin. Procedia Social and Behavioral Sciences. 19 (2011), 556566.

27. Rostami, N., \& Y. Kazemi., (2017). Flood risk zoning in the city of Ilam using AHP and GIS methodology. Research Project, Ilam University (in Persian).

28. Soleimani Sardoo, F., 2009. Priority of effective regions on flood peak by using of RS \& GIS Techniques and HEC- HMS model at Halilrud, Isfahan University of Technology, Faculty of Natural Resources, p, 130.

29. Stefanidis, S., \& D. Stathis., (2013). Assessment of flood hazard based on natural and anthropogenic factors using analytic hierarchy process (AHP). Natural hazards. 68(2), 569585.

30. Yeganeh. N., \& S. Sabri., (2014). Flood Vulnerability Assessment in Iskandar Malaysia Using Multi-criteria Evaluation and Fuzzy Logic. Journal of Applied Sciences. Engineering and Technology. 8 (16), 1794-1806. 


\title{
Flood zoning of Bandar Abbas city and evaluation of the development trend of residential areas towards flood areas
}

\author{
Masumeh_Asadi1: Instructor of Geomorphology, Department of Social Sciences, Payame Noor University, \\ Tehran, Iran
}

Kamyar Emami: Masters of Geomorphology-Hydrogeomorphology in Environmental planning. Faculty of Geography, University of Tehran, Tehran

Article History (Received: 2021/01/27

Accepted: 2021/05/16)

\section{Extended abstract}

\section{1- Introduction}

An examination of the number of floods in recent years shows that floods are no longer a rare sudden disaster, but a growing phenomenon that, at any given time, causes a lot of damage, including life and death. As a result of interference in natural environments, the presence of multiple structures, and the lack of appropriate measures to protect these environments, flood conditions are provided. Also, with the rapid growth of urban development and the creation and development of infrastructure, floods in urban areas have become more and more severe. In our country, especially in the southern regions of the country, due to climatic conditions, floods are frequent and harmful. The growing trend of floods in recent years suggests that most of the country's southern cities are at risk of flooding. According to studies, about 40 large and small floods occur in different parts of the country every year. Experimental and managerial experience of different countries shows that the first step in reducing the harmful effects of floods is to identify flooding areas and zoning of these areas in terms of flood risk so that based on the results obtained with integrated management. And comprehensive urban planning prevented the harmful effects of urban floods as much as possible. This study aims at identifying potential flood areas of Bandar Abbas and Bandar Abbas strategic city using GIS, and adapting this map to the development plan of residential areas obtained from LCM model in remote sensing of satellite images as well as determining the flood risk areas.

\section{2-Materials and methods}

In this study, two steps have been taken to achieve the desired goals. In the first stage, using five height parameters, slope, land-use, lithology, and river mile have been used as effective parameters in identifying flood-prone areas. After preparing the information layers for each parameter, the layers are standardized using fuzzy logic. After standardizing the layers, a hierarchical analysis model (AHP) was used to weight the layers. After determining the weight of each layer, in the ArcGIS environment, the weight obtained is applied to that layer, and finally, using fuzzy gamma, the information layers are combined, and the final map of flood-prone areas is prepared. In the second phase, satellite imagery from the 1990s, 2000s, 2010, and 2019 was used to assess the development of residential areas to prone to flood-prone areas. After preparing the images, in the ENVI software, first the necessary preprocessing on the images, including radiometric and atmospheric studies, has been done, and then by using the maximum probability method, land-use maps of the study area related to

\footnotetext{
${ }^{1}$ Corresponding Author, Email: asadi_zhina@yahoo.com.
} 
the 1990s, 2000s, prepared in 2010 and 2019, were presented. After preparing the land use maps, IDRISI software and the LCM (Land Change Modeler) software were used to evaluate the trend of land-use change in residential areas.

\section{3-Discussion and results}

Evaluation of the final results of flood-prone areas indicates that a large part of the study area has a high flood-rising potential, so based on the results, the class has a very high potential for floods, $88 \mathrm{~km}^{2}$ (equivalent to $28.7 \%$ of the study area). The study area includes mainly areas close to the river, low-slope, and low-lying areas. Also, the class with a very low potential for flooding includes $24 \mathrm{~km}^{2}$ (equivalent to $7.8 \%$ of the study area) of the study area, which mainly includes the highlands and the northern slope of the study area. In addition, the results of the assessment of land-use changes indicate that land-use has undergone many changes during the study period, and the use of residential areas has increased. Assessing the trend of changes, shows that the increasing trend of use of residential areas has been due to population growth and construction development. The decrease in the use of vegetation and water area is also due to the development of the use of residential areas, which has caused the destruction of vegetation and the progress towards the coast. Also, the trend of changes in the use of weak pastures and salt marshes has been affected by the development of residential areas and climate change.

\section{4-Conclusion}

The results indicate that the study area has a high potential for flooding, so that about 170 $\mathrm{km}^{2}$ of the study area (equivalent to $55 \%$ of the study area) have a high and very high flood potential these areas mainly include low-slope and low-lying areas of the urban area and the suburbs of Bandar Abbas. Therefore, in terms of used parameters, the city of Bandar Abbas has a high potential for flooding. Also, in this research, the trend of land-use changes and residential areas of the study area has been evaluated. According to the results, the use of residential areas (including residential areas and man-made areas) has grown so much that in 1990 , this area was $32.2 \mathrm{~km}^{2}$, which in 2000 to 42.9 , and in 2010 it increased to $55.7 \mathrm{~km}^{2}$ and in 2019 to $77.4 \mathrm{~km}^{2}$. Assessing the spatial trend of land use changes indicates that a large part of the residential area has moved to areas prone to flooding. According to the results, in 1990, $14.2 \mathrm{~km}^{2}$ of residential areas were located on the potential floor of many floods, which in 2000 to 16.4 , in 2010 to 21.9 and in 2019 , it has increased to $28.1 \mathrm{~km}^{2}$. Therefore, it can be said that in recent years, a large part of the residential areas has moved to flood-prone areas.

5-Keywords: Bandar Abbas, Flood, Land use change 